\title{
Assessment of uncertainties of an aircraft-based mass balance approach for quantifying urban greenhouse gas emissions
}

\author{
M. O. L. Cambaliza ${ }^{1}$, P. B. Shepson ${ }^{1,2}$, D. R. Caulton ${ }^{1}$, B. Stirm ${ }^{3}$, D. Samarov $^{5}$, K. R. Gurney ${ }^{9}$, J. Turnbull ${ }^{6}$, \\ K. J. Davis ${ }^{4}$, A. Possolo ${ }^{5}$, A. Karion ${ }^{7,8}$, C. Sweeney ${ }^{7,8}$, B. Moser $^{1}$, A. Hendricks ${ }^{1}$, T. Lauvaux ${ }^{4}$, K. Mays ${ }^{1}$, \\ J. Whetstone ${ }^{5}$, J. Huang ${ }^{9}$, I. Razlivanov ${ }^{9}$, N. L. Miles ${ }^{4}$, and S. J. Richardson ${ }^{4}$ \\ ${ }^{1}$ Department of Chemistry, Purdue University, West Lafayette, IN, USA \\ ${ }^{2}$ Department of Earth, Atmospheric and Planetary Science \& Purdue Climate Change Research Center, \\ Purdue University, West Lafayette, IN, USA \\ ${ }^{3}$ Department of Aviation Technology, Purdue University, West Lafayette, IN, USA \\ ${ }^{4}$ Department of Meteorology, The Pennsylvania State University, University Park, PA, USA \\ ${ }^{5}$ NIST, Gaithersburg, MD, USA \\ ${ }^{6}$ National Isotope Centre, GNS Science, Lower Hutt, New Zealand \\ ${ }^{7}$ University of Colorado, Boulder, CO, USA \\ ${ }^{8} \mathrm{NOAA} / \mathrm{ESRL}$, Boulder, CO, USA \\ ${ }^{9}$ School of Life Sciences, Arizona State University, Tempe, AZ, USA
}

Correspondence to: M. O. L. Cambaliza (mcambali@purdue.edu)

Received: 23 July 2013 - Published in Atmos. Chem. Phys. Discuss.: 14 November 2013

Revised: 30 May 2014 - Accepted: 24 July 2014 - Published: 2 September 2014

\begin{abstract}
Urban environments are the primary contributors to global anthropogenic carbon emissions. Because much of the growth in $\mathrm{CO}_{2}$ emissions will originate from cities, there is a need to develop, assess, and improve measurement and modeling strategies for quantifying and monitoring greenhouse gas emissions from large urban centers. In this study the uncertainties in an aircraft-based mass balance approach for quantifying carbon dioxide and methane emissions from an urban environment, focusing on Indianapolis, IN, USA, are described. The relatively level terrain of Indianapolis facilitated the application of mean wind fields in the mass balance approach. We investigate the uncertainties in our aircraft-based mass balance approach by (1) assessing the sensitivity of the measured flux to important measurement and analysis parameters including wind speed, background $\mathrm{CO}_{2}$ and $\mathrm{CH}_{4}$, boundary layer depth, and interpolation technique, and (2) determining the flux at two or more downwind distances from a point or area source (with relatively large source strengths such as solid waste facilities and a power generating station) in rapid succession, assuming that the emission flux is constant. When we quantify the precision in the approach by comparing the estimated emis-
\end{abstract}

sions derived from measurements at two or more downwind distances from an area or point source, we find that the minimum and maximum repeatability were 12 and $52 \%$, with an average of $31 \%$. We suggest that improvements in the experimental design can be achieved by careful determination of the background concentration, monitoring the evolution of the boundary layer through the measurement period, and increasing the number of downwind horizontal transect measurements at multiple altitudes within the boundary layer.

\section{Introduction}

The persistent and uncertain future consequences of global climate change are principally driven by the addition of greenhouse gases to the atmosphere. Although a brief decline in global fossil fuel emissions due to the recent global financial crisis in 2009 was observed, the following year saw a steep rebound in emissions that reached a record high of approximately $9.1 \pm 0.5$ petagrams of carbon $(\mathrm{PgC}$ ) (Peters et al., 2012). This value combined with emissions from landuse change $(0.9 \pm 0.7 \mathrm{PgC})$ results in a total anthropogenic 
emission estimate of $10.0 \pm 0.9 \mathrm{PgC}$ for the year 2010 (Peters et al., 2012). Relative to pre-industrial concentrations, the present-day increases in atmospheric $\mathrm{CO}_{2}$ and $\mathrm{CH}_{4}$, two of the most important anthropogenic greenhouse gases, have a combined radiative forcing of $\sim 2.1 \mathrm{~W} \mathrm{~m}^{-2}$ in 2005 , or about $81 \%$ of the anthropogenic forcing from total longlived greenhouse gases (Forster et al., 2007).

The global fossil fuel $\mathrm{CO}_{2}$ emission rate is considered to be well known, but uncertainties are growing because of increasing contributions from emerging economies (Gregg et al., 2008; Marland, 2008; Peters et al., 2012). Whereas the uncertainty in fossil fuel emissions from the United States and European countries is estimated to be on the order of 3-5\% (Marland, 2012), recent findings using national and aggregated provincial energy statistics have shown that the uncertainty in fossil fuel $\mathrm{CO}_{2}$ emissions from China is $18 \%$, which is equivalent to $0.38 \mathrm{PgC}$ ( $1.4 \mathrm{Gt}$ of carbon dioxide) (Guan et al., 2012; Marland, 2012) and greater, for example, than Japan's reported fossil fuel emission for 2008 (Boden et al., 2010; Marland, 2012). Considerable uncertainty, from 10 to $40 \%$, between emission inventories, is also observed at the regional level even for countries with relatively stable economies (Peylin et al., 2011). Large uncertainties in fossil fuel emissions were also observed for inventories of geopolitical units smaller than nations (Gurney et al., 2009; Ciais et al., 2010). For example, Gurney et al. (2009) estimate a $16 \%$ uncertainty in the bottom-up emission approach at the state level and up to $50 \%$ at the county level in the United States. Considerable differences in flux estimates between bottomup and top-down approaches have also been reported in the regional (Bergamaschi et al., 2010) and city scales (Mays et al., 2009; Wunch et al., 2009; Brioude et al., 2013). The magnitude of these uncertainties is such that it calls into question the ability of nations who may commit to mitigation activities to determine the effectiveness of their approaches - for example, a reduction target of $10 \%$ by 2020 could be difficult to substantiate with such uncertainty levels.

Human activities are focused in and around cities, where the majority of the energy produced for electricity and transportation is consumed. In the coming decades, cities will be critical in the global effort to both mitigate and adapt to the consequences of climate change. By 2030, approximately $74 \%$ of $\mathrm{CO}_{2}$ worldwide is predicted to be emitted from cities (World Bank, 2010; IEA Report, 2008), and in the US, that figure is $87 \%$. Approaches must be in place to verify compliance to future emissions mitigation agreements, preferably those based on atmospheric measurements. McKain et al. (2012) suggest that remote sensing methods such as column observations from satellite or ground-based measurements are ideal approaches for detecting emission trends from urban environments. More recently, Kort et al. (2012) demonstrated the potential of satellite-based measurements to distinguish fossil fuel signals from megacities relative to background regions for long-term monitoring of emission trends, but also mentioned the need for other methods to support and validate space-based retrievals.

Here, we describe and evaluate an aircraft-based mass balance approach for quantifying fossil fuel emissions in urban environments using Indianapolis, IN, as a case study. This study is part of the Indianapolis Flux Experiment (INFLUX), a multi-institution collaborative project that aims to develop, assess, and improve bottom-up and top-down approaches for quantifying greenhouse gas emissions from urban environments, using Indianapolis as a case study. As part of INFLUX, there are currently 12 instrumented towers in Indianapolis that are monitoring the abundances of greenhouse gases using in situ cavity ring-down spectroscopy and flask sampling (http://influx.psu.edu). Aside from the aircraft-based mass balance approach, tower and aircraft in situ and flask data will be combined with inverse modeling to independently estimate the $\mathrm{CO}_{2}$ and $\mathrm{CH}_{4}$ emissions from Indianapolis. Results from these top-down approaches will be compared with the Hestia bottom-up approach (Gurney et al., 2012).

Aircraft-based mass balance methods have been used to quantify the emissions from urban regions (Kalthoff et al., 2002; Mays et al., 2009; Trainer et al., 1995; Turnbull et al., 2011; White et al., 1976, 1983) as well as from point and area sources (Karion et al., 2013b; Peischl et al., 2013; Ryerson et al., 2001; Walter et al., 2012; Wratt et al., 2001). In this work, we investigate the uncertainty of an aircraftbased mass balance approach for estimating urban fluxes by (1) assessing the sensitivity of the estimated citywide $\mathrm{CO}_{2}$ and $\mathrm{CH}_{4}$ fluxes for several flight experiments due to the uncertainties in the measurement and analysis parameters, i.e., regional background concentration of $\mathrm{CO}_{2}$ and $\mathrm{CH}_{4}$, depth of the convective boundary layer, magnitude of the perpendicular wind speed, and choice of the interpolation technique used in the mass balance calculations, and (2) determining the flux at two or more downwind distances from a point or area source in rapid succession, assuming that the emission rate is constant.

A total of seven flight experiments were analyzed in this study. In Sect. 2 (Methods) and Sect. 3 (Results and discussion), we describe and discuss in detail the (1) experimental flight plan and flux calculations, (2) three Indianapolis flight experiments that were used in the sensitivity analyses, and (3) four flight experiments downwind of relatively strong $\mathrm{CO}_{2}$ and $\mathrm{CH}_{4}$ emitters (a power generating station and two landfills) to assess the precision of the approach. From our analyses, we identify the most important parameters that affect the flux, and use these insights to recommend improved experimental approaches for urban-area-wide aircraft-based flux measurements. 


\section{Methods}

\subsection{Site description and bottom-up data}

As of the recent 2010 census, Indianapolis $\left(39.79^{\circ} \mathrm{N}, 86\right.$. $15^{\circ} \mathrm{W} ; 219 \mathrm{~m}$ mean elevation above sea level; Fig. 1) is the 12th most populous city in the United States (http://census. gov, accessed 9 April 2012). The city of Indianapolis is an ideal test area for evaluating and improving measurement strategies for quantifying urban-scale fossil fuel emissions. Indianapolis is sufficiently removed from other metropolitan areas and is surrounded by cropland, and thus its fossil fuel signal above background should be relatively easily identified. Mays et al. (2009) reported an average $\mathrm{CO}_{2}$ flux of $19 \mu \mathrm{mol} \mathrm{m}^{-2} \mathrm{~s}^{-1}\left(14000 \mathrm{~mol} \mathrm{~s}^{-1}\right)$ from nine Indianapolis flight experiments in 2008 and 2009. This emission flux to the atmosphere distributed uniformly across a $50 \mathrm{~km}$ urban surface in a $\sim 1000 \mathrm{~m}$ deep boundary layer and advected with winds of $\sim 3 \mathrm{~m} \mathrm{~s}^{-1}$ magnitude will yield an enhancement of $2-3 \mathrm{ppm}$ in the boundary layer downwind of the city. This is consistent with long-term daytime observations of 2-3 ppm average enhancement (and is as large as 5-10 ppm) from our tower network (Miles et al., 2013). Indianapolis is also characterized by flat terrain, making the meteorology relatively simple. The Vulcan high-resolution data product (Gurney et al., 2009) shows that the fossil fuel $\mathrm{CO}_{2}$ emission rate from Marion County (equivalent to the city of Indianapolis) in 2002 was $\sim 3.6 \mathrm{Mt} \mathrm{Cyr}^{-1}$, providing a relatively large signal that can be easily detected by aircraft- and tower-based measurement systems (see also http://vulcan.project.asu.edu/). More recently, Gurney et al. (2012) quantified all fossil fuel emissions from Indianapolis at much finer spatial and temporal scales down to the building and street levels, at hourly timescales, for the year 2002 (see also http://hestia.project. asu.edu/). This comprehensive downscaling study provides an independent estimate of the fossil fuel $\mathrm{CO}_{2}$ flux from the city to which we will compare emission estimates from top-down approaches such as the aircraft-based mass balance method presented here.

\subsection{Aircraft-based measurements of greenhouse gases and meteorological parameters}

Several flight experiments were conducted in 2011 downwind of Indianapolis, IN, using Purdue University's Airborne Laboratory for Atmospheric Research (http://science.purdue. edu/shepson/research/bai/alar.html). The aircraft platform is a Beechcraft Duchess, a modified twin-engine aircraft with a compartment space of $\sim 1 \mathrm{~m}^{3}$ for instrumentation. It is equipped with (1) a global positioning and inertial navigation system (GPS/INS), (2) a Best Air Turbulence (BAT) probe for wind measurements (Garman et al., 2006), (3) a cavity ring-down spectroscopic system for real-time, in situ measurement of greenhouse gas concentrations (Crosson, 2008; Karion et al., 2013a), (4) an in-flight $\mathrm{CO}_{2} / \mathrm{CH}_{4}$ calibration system, and (5) a programmable flask package (PFP) for discrete sampling of ambient air.

Concentrations of methane, carbon dioxide and water were measured at a frequency of $0.5 \mathrm{~Hz}$ using an in situ flightready Picarro cavity ring-down spectrometer (CRDS) model number G2301- $f$ (Crosson, 2008; Chen et al., 2010; Karion et al., 2013a). Ambient air from the nose of the aircraft was pulled through a $5 \mathrm{~cm}$ diameter PFA Teflon tube at a flow rate of $1840 \mathrm{~L} \mathrm{~min}^{-1}$ (equivalent to a $\sim 0.1 \mathrm{~s}$ residence time) using a blower installed at the rear of the aircraft. Teflon was used to minimize adsorptive losses for volatile organic compounds (VOCs), which are also sampled with the aircraft. The CRDS was connected to the Teflon tubing via a "T" connection, pumping air continuously through the analyzer. Because the flow rate through the analyzer is 450 standard $\mathrm{mL} \mathrm{min}^{-1}$, the time required to purge the sampling system was determined to be $\sim 6.7 \mathrm{~s}$. In-flight calibrations for $\mathrm{CO}_{2}$ and $\mathrm{CH}_{4}$ were achieved using a valve-switching calibration system and three NOAA/ESRL reference cylinders with the following mole fractions: $378.49,408.83$, and $438.29 \mathrm{ppm}$ for $\mathrm{CO}_{2}$, and 1803.0, 2222.2, and $2599.5 \mathrm{ppb}$ for $\mathrm{CH}_{4}$, respectively (Dlugokencky et al., 2005; Zhao and Tans, 2006). Supplement Fig. S1a and b show in-flight calibration curves for $\mathrm{CO}_{2}$ and $\mathrm{CH}_{4}$ for several flight experiments, showing excellent reproducibility of the indicated concentrations over 5 months (near-zero drift), and good linearity. The measurement precision for $\mathrm{CO}_{2}$ and $\mathrm{CH}_{4}$ during in-flight calibrations was $0.1 \mathrm{ppm}$ and $2.6 \mathrm{ppb}$, respectively. Residuals from the fit ranged from -2.6 to $3.9 \mathrm{ppb}$ for $\mathrm{CH}_{4}$ and from -0.1 to $0.2 \mathrm{ppm}$ for $\mathrm{CO}_{2}$.

In addition to in situ spectroscopic measurements of $\mathrm{CO}_{2}$ and $\mathrm{CH}_{4}$ mole fractions, discrete grab samples of ambient air were obtained using the PFP, which were later analyzed at NOAA for a suite of trace gases ( $\sim 55$ species) (methods described at http://esrl.noaa.gov/gmd/ccgg/aircraft/analysis. html). The PFP consists of twelve $700 \mathrm{~mL}$ glass flasks that are pressurized to $2.7 \mathrm{~atm}$. Supplement Fig. S2 shows excellent linearity $\left(R^{2}=0.99\right)$ with slopes identical to unity at $95 \% \mathrm{CL}$ (confidence level) between the $\mathrm{CO}_{2}$ and $\mathrm{CH}_{4}$ concentrations obtained from continuous measurements with the CRDS and grab sampling with the PFP for several flight experiments. To obtain enough air for radiocarbon measurements, two flasks were filled simultaneously (Turnbull et al., 2011). The first flask was analyzed for greenhouse gases, hydrocarbons, and halocarbons, as well as stable isotopes of carbon dioxide and methane $\left(\delta^{13} \mathrm{CO}_{2}, \delta^{13} \mathrm{CH}_{4}\right)$ (methods and calibration scales described at http://www.esrl.noaa. gov/gmd/ccl/scales.html; Montzka et al., 1993; Vaughn et al., 2004). The second flask was dedicated to ${ }^{14} \mathrm{CO}_{2}$ measurement (Turnbull et al., 2007). Previous work (Turnbull et al., 2011) has shown that there is no significant difference in trace gas mixing ratios between the two simultaneously filled flasks.

To investigate any potential systematic bias in the concentration measurements, we estimate the concentration 


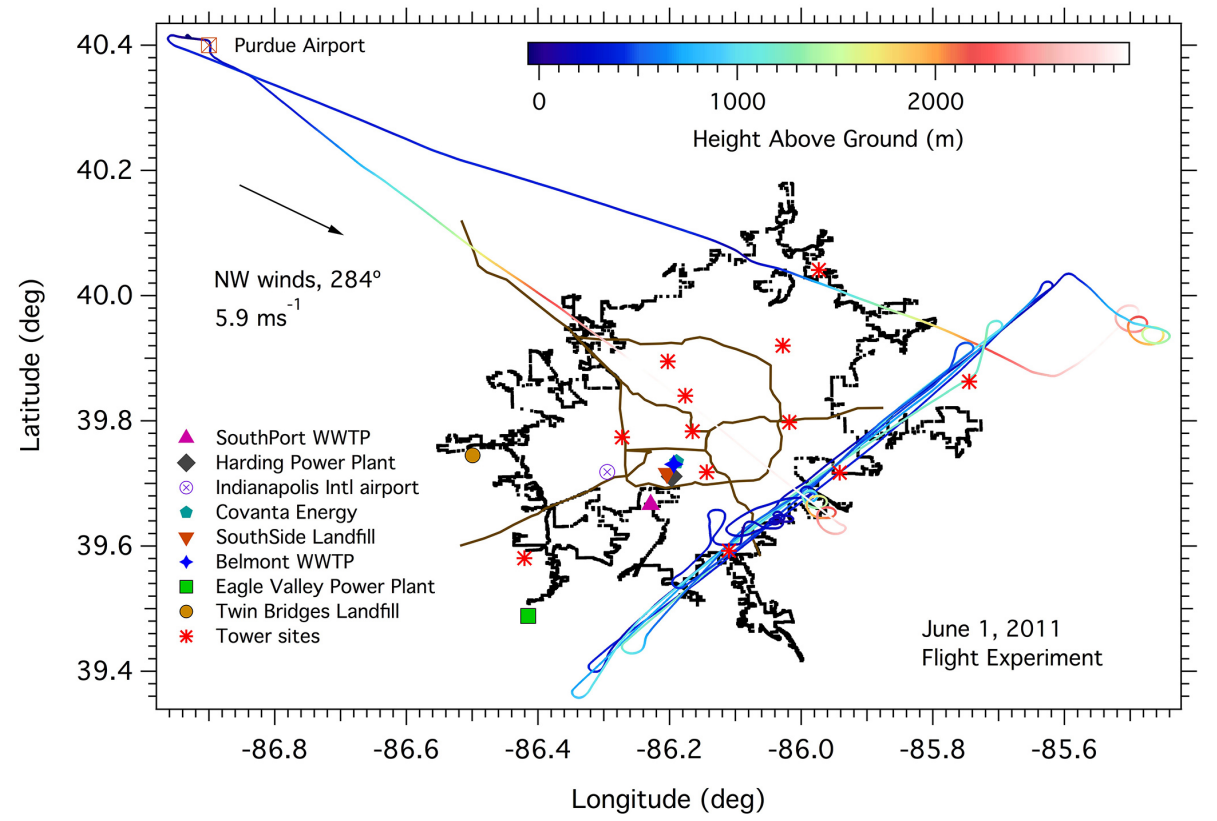

Figure 1. Flight path as a function of altitude downwind of Indianapolis, IN, USA on 1 June 2011. Mean winds were from the northwest at $\sim 6 \mathrm{~m} \mathrm{~s}^{-1}$. Also shown are the locations of $\mathrm{CO}_{2}$ and $\mathrm{CH}_{4}$ sources within and around the city limits such as power plants (Harding Street and Eagle Valley power generating facilities), landfills, incineration plant (Covanta Energy), and wastewater treatment plants (Belmont WWTP and Southport WWTP). The brown outline represents the major highways inside the city.

measurement uncertainty as the average difference between the CRDS measurements and the $\mathrm{CO}_{2}$ and $\mathrm{CH}_{4}$ mole fractions simultaneously obtained from discrete flask sampling (Supplement Fig. S2). The $\mathrm{CO}_{2}$ and $\mathrm{CH}_{4}$ concentrations in flask samples were determined using non-dispersive infrared analysis (NDIR) (Conway et al., 1994; see also method description at http://www.esrl.noaa.gov/gmd/ccgg/ aircraft/analysis.html, accessed 21 February 2013) and gas chromatography (GC) (Dlugokencky et al., 1994), respectively. We find that the relative differences between the CRDS and flask measurements are randomly distributed around zero for both $\mathrm{CO}_{2}$ and $\mathrm{CH}_{4}$ (Supplement Fig. S3). On the basis of this analysis, there is no apparent systematic bias in the CRDS measurements.

Wind vectors were measured at $50 \mathrm{~Hz}$ using the BAT probe, a nine-port pressure probe extending from the nose of the aircraft (Garman et al., 2006, 2008). The measured pressure differentials across the hemisphere of the probe are combined with $50 \mathrm{~Hz}$ inertial information from the GPS/INS system to yield the 3-D wind distribution. The accuracy in the horizontal wind measurements was determined by Garman (2009) to be $\pm 0.4 \mathrm{~m} \mathrm{~s}^{-1}$. At the center of the hemisphere is a microbead thermistor for ambient temperature measurements.

\subsection{Experimental flight design}

The experimental flight design was discussed in full detail by Mays et al. (2009). In summary, flight experiments were conducted between 11:00 and 16:00 LT (local time) when the boundary layer was generally fully developed. Prior to each flight experiment, the prevailing wind direction was estimated using the Hybrid Single Particle Lagrangian Integrated Trajectory Model (HYSPLIT; Draxler and Rolph, 2012). The aircraft heading was such that the ground track was perpendicular to the wind direction determined from the HYSPLIT back trajectory at $500 \mathrm{~m}$ a.g.l. (above ground level), and from surface wind reports in-flight. The magnitude of the winds was also monitored a couple of hours before the start of the experiment so as to avoid conditions in which calm morning winds could lead to accumulation prior to outflow. Constant altitude horizontal transects were conducted downwind of Indianapolis at various altitudes up to the top of the convective boundary layer. The city of Indianapolis is about $70 \mathrm{~km}$ wide, and each horizontal transect was $\sim 90$ to $100 \mathrm{~km}$ long so that regional background concentrations of methane and carbon dioxide could be estimated from the edges of the transects. By flying perpendicular to the wind direction on level flight paths at multiple altitudes in the boundary layer, the aircraft intercepted and detected elevated concentrations of $\mathrm{CO}_{2}$ and $\mathrm{CH}_{4}$ directly downwind of anthropogenic sources from the urban environment in a two-dimensional plane. Two to three hours of flight time were used to generate a rastered 2-D vertical plane. Given a typical aircraft speed of $70 \mathrm{~m} \mathrm{~s}^{-1}$ and CRDS measurement frequency of $0.5 \mathrm{~Hz}$, the horizontal resolution within the plane was $140 \mathrm{~m}$. The depth of the convective boundary layer (CBL) was determined from vertical 
profile measurements of water vapor, potential temperature, and variance of the vertical wind speed, during which the aircraft ascended and descended in a spiral path from the surface up to a height of $\sim 4000 \mathrm{~m}$ a.g.l. in the free troposphere.

Figure 1 shows, for example, the flight path as a function of altitude downwind of Indianapolis on 1 June 2011. The black outline shows the city boundary of Indianapolis based on the 2010 US Census population density of an urbanized area (http://www.census.gov/geo/www/ua/uafaq. html, accessed 26 November 2012), which encloses regions that have population densities of $\geq 390$ people $\mathrm{km}^{-2}$. For this particular experiment, two sets of vertical profiles were performed, one before and one after the horizontal transects. The first vertical profile was conducted outside the city limits, while the second was flown directly downwind of the city. The location of carbon dioxide and methane sources such as power generating facilities, an incineration plant, landfills, and wastewater treatment plants within and outside the city limits are also shown in the figure. We note that the Harding Street power plant (HSPP) and the Southside landfill, the largest $\mathrm{CO}_{2}$ and $\mathrm{CH}_{4}$ sources in Indianapolis, respectively, are almost colocated on the southwest side of the city, separated only by a distance of about $1 \mathrm{~km}$. The brown outline shows the major highways and arterial roads that traverse into and around the city.

\subsection{Emission rate calculation}

The flux or mass flow rate of species $\mathrm{C}$ through a crosswind plane downwind of the city is estimated by the integration of the enhancement above the background concentration $[C]_{\mathrm{b}}$ combined with the component of the wind perpendicular to the plane (Trainer et al., 1995; White et al., 1983), as shown in Eq. (1).

$$
F=\int_{z=z(s f c)}^{z_{i}} \int_{-x}^{x}\left([C]-[C]_{\mathrm{b}}\right) \times U_{\perp} \mathrm{d} x \mathrm{~d} z
$$

In Eq. (1), $z_{i}$ is the depth of the convective boundary layer, $z(s f c)$ is the ground level, and $-x$ and $+x$ are the horizontal limits of the plume width from an arbitrary midpoint. The full integration over the limits of the plane yields an emission rate, in $\mathrm{mol} \mathrm{s}^{-1}$.

In our analysis, the observed horizontal flight distributions for $\mathrm{CH}_{4}, \mathrm{CO}_{2}$, temperature, pressure, and perpendicular wind speeds were interpolated in a two-dimensional gridded plane using a kriging approach (Matlab-based EasyKrig3.0; Chu, 2004). We use a 10 s running average of the $50 \mathrm{~Hz}$ perpendicular wind speed to obtain the magnitude of the sustained winds at each altitude. During interpolation, a semivariogram of the data is calculated and modeled using the variogram model specified in Eq. (1) of Mays et al. (2009). The parameters of the model (power, nugget, sill, range, and length) are adjusted to achieve an optimum fit to the empirical semivariogram of the data. The quality of the interpolation is assessed using the Q1 (distribution of the deviation for the mean) and Q2 (distribution of deviations for the standard deviation) criteria (Chu, 2004). The raw data were interpolated using a $20 \mathrm{~m} \times 200 \mathrm{~m}$ kriging resolution in the vertical and horizontal directions, respectively.

Using the measured mean wind direction, the edges of the city are projected onto the horizontal transect to define the $-x$ and $+x$ horizontal limits of integration. The section in the transect outside the projected city limits is used to calculate the mean background concentration $[\bar{C}]_{\mathrm{b}}$, which was then subtracted from the gridded 2-D concentrations, $[C]_{x z}$, to obtain the enhancement from the city plume. In our approach, the background mole fractions determined from the edges of the city is assumed to be equivalent to the inflow of background air in the upwind side of the city. The net molar concentration at each grid cell $\left(\mathrm{mol} \mathrm{m}^{-3}\right)$ was then determined from the ideal gas law, as well as the interpolated pressure and temperature distributions. This incremental concentration was subsequently multiplied by the mean component of the gridded wind speed perpendicular to the 2-D plane $\left(\bar{U}_{\perp}\right)$, calculated at each altitude, to determine the net flux of molecules across each grid cell. Finally, the citywide emission rate, $F\left(\mathrm{~mol} \mathrm{~s}^{-1}\right)$, was calculated by integrating the net perpendicular molecular flow over the vertical and horizontal dimensions as described in Eq. (1). In this relationship, $\mathrm{d} x$ and $\mathrm{d} z$ are the horizontal and vertical grid spacing $(\mathrm{m})$ corresponding to the kriging resolution of 200 and $20 \mathrm{~m}$, respectively; $[\bar{C}]_{\mathrm{b}}$ is the mean background molar concentration; and $-x$ and $+x$ are the effective horizontal boundaries of the city determined from projecting the city limits onto the horizontal transect plane. We refer to this analysis method as the multi-transect kriging approach.

\subsection{Sensitivity analyses}

To develop an understanding of the relative importance of factors influencing the flux measurement uncertainty, we conducted a sensitivity analysis of the multi-transect kriging approach. Three flight experiments downwind of Indianapolis conducted on 1 March, 29 April, and 1 June 2011 were considered for these analyses. In the supplementary information we include the flight paths for the 1 March and 29 April 2011 flight experiments (Supplement Fig. S4). We investigate the magnitude of the change in the flux as a function of the uncertainties of three parameters: background $\mathrm{CO}_{2}$ and $\mathrm{CH}_{4}$, depth of and changes in the convective boundary layer height, and perpendicular wind speed. We also quantified the change in the flux as a function of the choice of interpolation method (Clyde and George, 2004), and the impact of interpolation to the surface. Supplement Table S1 provides a summary of the uncertainties in the analyses parameters.

The background concentrations were obtained from the edges of the gridded two-dimensional $\mathrm{CO}_{2}$ and $\mathrm{CH}_{4}$ matrices outside the city boundaries. We examined the influence of the background on the estimated flux in two ways. First, 
we compared the resulting flux using a vertically varying background, as well as from background concentrations that were averaged over the boundary layer. We determined the vertical distribution of the background (Supplement Fig. S5) by calculating the mean over $20 \mathrm{~m}$ altitude bins, which correspond to the kriging resolution in the vertical direction. Second, we calculated the sensitivity of the flux estimate to the uncertainty in the mean background concentration, i.e., $\Delta$ Flux $/ \Delta b$, where $\Delta$ Flux is the change in the flux and $\Delta b$ is the mean background concentration uncertainty, which is a combination of the measurement accuracy and observed background variability. We calculated the standard deviation in the mean background concentration at each altitude using the method described by Lenschow and Stankov (1986), where the variability in the measured parameter was shown to be dependent on the averaging length and the CBL depth. As described in Sect. 2.2., there is no apparent systematic bias in the CRDS measurements. Thus $\Delta b$ is attributed to the observed variability in the mean background concentrations, where the variability is defined as the standard deviation of the mean background concentration converted to a $95 \%$ CL. The uncertainty in the background is not constant with altitude (Supplement Fig. S5). The average uncertainties in the $\mathrm{CO}_{2}$ and $\mathrm{CH}_{4}$ mean background concentrations were determined to be $0.3,0.2$, and $0.5 \mathrm{ppm}$ and $1.3,3.2$, and $2.6 \mathrm{ppb}$ for the 1 March, 29 April, and 1 June 2011 flight experiments, respectively.

To investigate the influence of the uncertainty in the wind speed on the estimated flux, we calculated $\Delta$ Flux / $\Delta U_{\perp}$, where $\Delta U_{\perp}$ is the uncertainty in the perpendicular wind speed. As stated above, we calculated the mean perpendicular wind speed $\left(\bar{U}_{\perp}\right)$ at each altitude and estimated the variability by determining the standard deviation of the mean (Lenschow and Stankov, 1986). The calculated systematic uncertainty in the BAT probe for horizontal wind measurements was determined by Garman (2009) to be $0.4 \mathrm{~m} \mathrm{~s}^{-1}$. We propagated the systematic uncertainty with the calculated variability to obtain the overall measurement uncertainty $\Delta U_{\perp}$ converted to a $95 \% \mathrm{CL}$. We find that the systematic uncertainty was significantly larger than the variability, such that the overall uncertainty in the perpendicular wind speed was determined to be $\sim 0.7 \mathrm{~m} \mathrm{~s}^{-1}$ for the three flight experiments. In our analyses we assume that the winds at the time of measurement are the same at the time of emission, as done and described in Trainer et al. (1995).

The change in flux due to the uncertainty in the convective boundary layer (CBL) height (height to which data are interpolated) was also investigated. We note that, for two of the three flight experiments considered in these analyses (1 March and 29 April 2011 experiments), one vertical profile was flown downwind of the city after the horizontal transects (Supplement Fig. S4), while two vertical profiles were obtained for the 1 June 2011 flight experiment (before and after the horizontal transects). Figure 2 shows the ascending vertical profiles of potential temperature $(\theta)$, its gradient of $\theta$ with altitude $(z)$, and $\mathrm{H}_{2} \mathrm{O}$. The altitude with the largest rate of change in $\theta$ (i.e., maximum $\mathrm{d} \theta / \mathrm{d} z$ ) is considered to be $z_{i}$, the altitude representing the top of the CBL. The CBL depths were determined to be 525 and $1110 \mathrm{~m}$ for the 1 March and 29 April experiments, respectively, and 1310 and $1880 \mathrm{~m}$ for the 1 June flight experiment before and after the horizontal transects, respectively. Supplement Fig. S6 shows the corresponding descending vertical profiles of $\theta$ and $\mathrm{H}_{2} \mathrm{O}$, while Supplement Fig. S7 shows the vertical profiles of $\mathrm{CO}_{2}$ and $\mathrm{CH}_{4}$. Supplement Table S2 summarizes the observed CBL depths for the three flight experiments.

We note that for the 1 June 2011 flight experiment, the depth of the CBL grew considerably $(\sim 570 \mathrm{~m})$ within the $4 \mathrm{~h}$ duration between the beginning and end of the experiment (panels c and d of Fig. 2). Thus, for this particular case, we calculate the base flux using the CBL depth halfway through the horizontal transects. To determine the CBL depth midpoint through the transects, we estimate the change in the CBL depth using the thermodynamic mixed-layer growth method (Stull, 1997):

$\Delta z=\left\lfloor\frac{2}{\gamma}\left[\overline{w^{\prime} \theta_{\mathrm{s}}^{\prime}}\right] \Delta t\right\rfloor^{\frac{1}{2}}$.

In this relationship, $\Delta z$ is the change in the CBL depth within the elapsed time $\Delta t, \gamma$ is the adiabatic lapse rate, and $\overline{w^{\prime} \theta_{\mathrm{s}}^{\prime}}$ is the surface sensible heat flux calculated from the observed fluctuations in the vertical winds and potential temperature during the horizontal transects.

Because two aircraft vertical profiles were performed during the 1 June 2011 experiment, it is possible to determine how well the thermodynamic mixed-layer growth model is able to predict the observed CBL depth. Given the measured CBL depth from the first vertical profile $(1310 \mathrm{~m})$, and calculating $\Delta z$ using Eq. (2), the predicted CBL depth at the end of the experiment (elapsed time $\Delta t=\sim 4 \mathrm{~h}$ ) was $\sim 1990 \mathrm{~m}$, which is $\sim 6 \%$ different from the observed CBL depth at that time $(1880 \mathrm{~m})$. Using this model, the predicted CBL height halfway through the horizontal transects was $1720 \mathrm{~m}$, the depth to which we evaluate the base flux for the 1 June 2011 flight experiment.

The CBL uncertainty was obtained from the regression plot of the standard deviation of $z_{i}\left(\sigma_{z_{i}}\right)$ versus $z_{i}$ determined by Davis et al. (1997) from the BOREAS (Boreal EcosystemAtmosphere Study) field campaign, where the dynamics of the CBL using a lidar system on an aircraft platform was intensively investigated. The high-frequency measurements with the lidar system (one $z_{i}$ measurement every $13 \mathrm{~m}$ ) allowed for the investigation of the variability of the CBL top over hundreds of kilometers due to updrafts (rising thermals) and downdrafts and the associated cascade of turbulence to smaller scales. $\sigma_{z_{i}}$ versus $z_{i}$ were determined for 12 cases of clear-air convection (12 different CBL depths) collected during 8 days of BOREAS field campaigns (Figure 15 in Davis et al., 1997). We evaluate the sensitivity in the estimated flux 

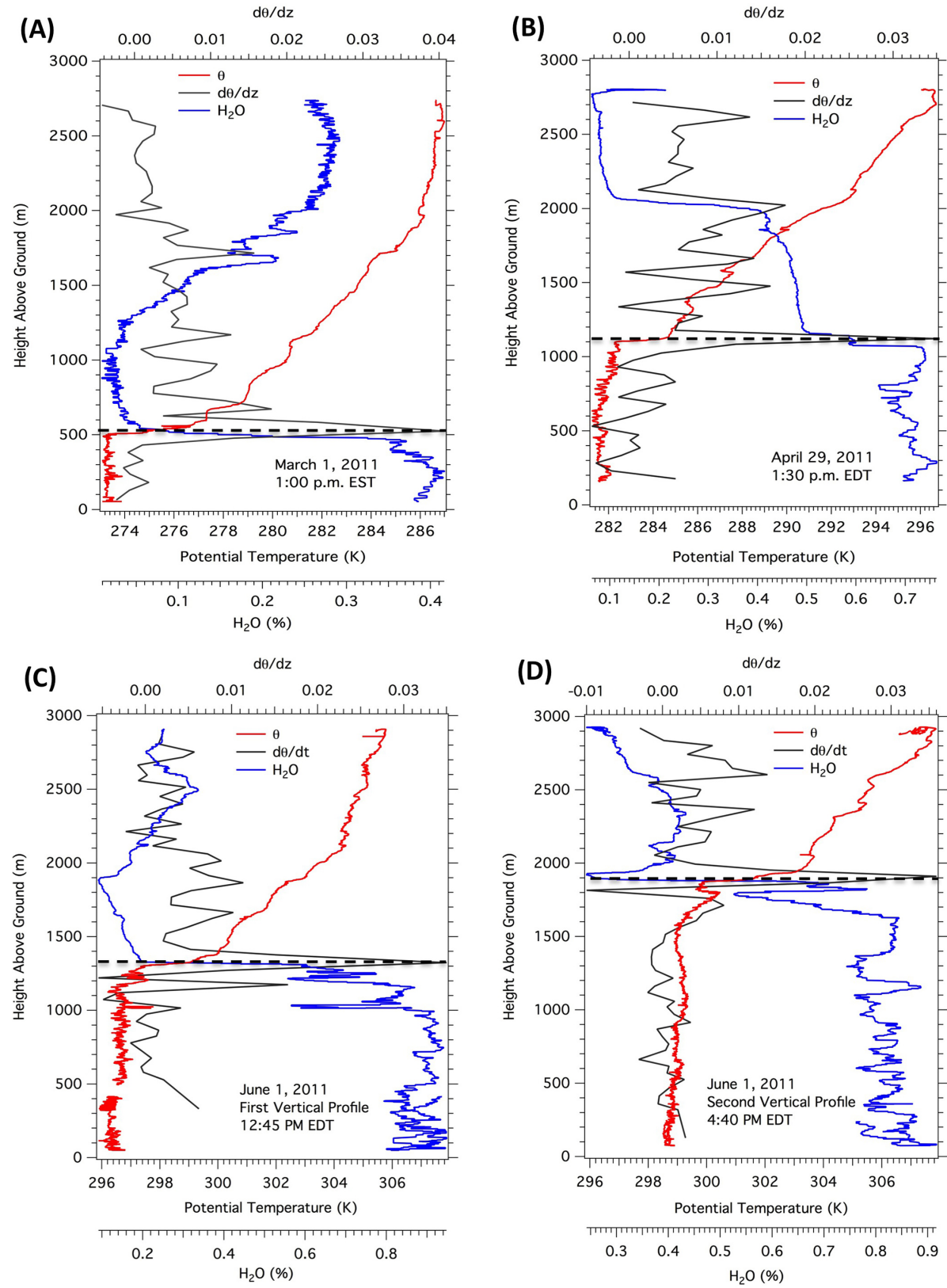

Figure 2. Vertical ascending profiles of $\mathrm{H}_{2} \mathrm{O}$, potential temperature $(\theta)$, and its gradient with altitude (d $\theta / \mathrm{d} z$ ) for (a) 1 March and (b) 29 April, and (c) 1 June 2011 before and (d) after the horizontal transects. Broken lines indicate the estimated CBL depths for the three flight experiments.

due to the uncertainty in the $\mathrm{CBL}$ depth corresponding to $\sigma_{z_{i}}$ at a $95 \% \mathrm{CL}$, which was determined to be 75,140 , and $204 \mathrm{~m}$ for 1 March, 29 April, and 1 June, respectively.

We also investigated the sensitivity of the flux to the choice of interpolation method. In all calculations of the base flux, the concentrations, perpendicular wind speed, pressure, and temperature were interpolated using the kriging method described above (Chu, 2010). To this end, we evaluated the change in the estimated flux when a different interpolation method was used. The alternative method was a version of the local polynomial regression (LPR) method (Fan and Gijbels, 1996), an established method for non-parametric regression. This method fits a $p$ th order polynomial regression to each point's immediate neighbors, and produces an interpolated value for the point based on the regression. The challenge with the use of LPR is the selection of the size and shape of these neighborhoods. For data with complex distributions exhibiting both fine and coarse features such as obtained from our flight experiments, adaptive neighborhoods were chosen to interpolate the data over the two-dimensional 
perpendicular plane. Numerous methods exist for selecting these adaptive neighborhoods. For the analysis presented here, we implemented the "fast regularization of the derivative expectation operator" method (Lafferty and Wasserman, 2008; Samarov, 2012).

We also recognize that the lack of data between the lowest altitude transect and the surface also contributes to the uncertainty estimates. Thus, we calculated the change in the $\mathrm{CO}_{2}$ and $\mathrm{CH}_{4}$ emissions for two cases: an extreme case, where we assumed that the city plume is not observed in a hypothetical transect between the surface and the lowest altitude measurement (i.e., assigning background values in the additional hypothetical transect), and a second case, where we assumed that the mole fractions in the hypothetical transect are the same as the lowest transect data. For both cases, we re-kriged the data and recalculated the emission rate, which is then compared with the result from the base case, the difference representing the surface extrapolation effect.

\subsection{Investigation of method precision using flux determinations from multiple downwind distances}

In this section, we describe our method for determining the precision of the aircraft-based mass balance approach using successive sequential measurement transects for two or more downwind distances from a point or area source. Four flight experiments were considered for these analyses. The flux is calculated using the multi-transect kriging approach and compared for the multiple sets of transects assuming that the emission from the source is constant over the full flux experiment period. To the extent that the emission source strength or the mixing height and turbulence in the boundary layer are not constant, this approach leads to an evaluation of an upper limit of the method precision, as all these changes will contribute to the overall precision of this approach. For point sources, the same experimental approach as described above for Indianapolis was used during the experiments but the horizontal transects were much shorter, as the sources were smaller in areal coverage. This allowed us to sample the plume repeatedly in rapid succession at finer vertical resolutions, thereby improving the representation of the plume during interpolation.

Two flight experiments were conducted at two downwind distances from the Newton County, IN, landfill on 16 June 2011 and 3 May 2012. The Newton County landfill received $\sim 2.9 \mathrm{Mt}$ of waste in 2008 for a daily average of $\sim 9500 t$ per operating day (http://www.in.gov/idem/files/solid_waste_fdr08.pdf,

accessed 15 May 2011). It is one of the three largest landfills in the United States (http://www.cnbc.com/ id/39382002/America_s_Largest_Landfills, accessed 6 September 2012; http://www.forbes.com/2010/10/13/ los-angeles-las-vegas-business-energy-biggest-landfills. html, accessed 6 September 2012).
We also measured the methane enhancements at two downwind distances from the Twin Bridges landfill (TBLF), Danville, IN, located about $30 \mathrm{~km}$ west of Indianapolis on 30 August 2012. For comparison, the Twin Bridges landfill received $\sim 0.72 \mathrm{Mt}$ of solid waste in 2008, a factor of 4 smaller than for the Newton County landfill for the same year (http: //www.in.gov/idem/files/solid_waste_fdr08.pdf, accessed 15 May 2011).

The $\mathrm{CO}_{2}$ plume was also sampled at three downwind distances from the HSPP station, located on the southwest side of Indianapolis, on 1 June 2012. This power generating facility emitted 3.2 Mt of $\mathrm{CO}_{2}$ in 2010 (http://ghgdata.epa.gov/ ghgp/main.do, accessed on 2 September 2012). The Newton County and Twin Bridges landfills as well as the Harding Street power generating station are idealized small area and point sources for testing the precision, as well as the accuracy (given the relatively well-known source strength data for the power plant) of the aircraft-based flux measurement approach. Their relatively large source strengths make the observed methane and carbon dioxide signals considerably enhanced relative to the background. Supplement Fig. S8 shows the flight paths as a function of downwind distances for the four experiments used in this analysis.

\subsection{Calculation of the citywide $\mathrm{CO}_{2}$ and $\mathrm{CH}_{4}$ flux from single-transect observations}

To examine the viability of a single-transect approach, we also calculated the citywide $\mathrm{CO}_{2}$ and $\mathrm{CH}_{4}$ emission fluxes using each transect independently for the 1 March, 29 April, and 1 June 2011 flight experiments, similar to the approach implemented in previous studies (Karion et al., 2013b; Peischl et al., 2013; Turnbull et al., 2011; Trainer et al., 1995; White et al., 1983). We carried out these calculations with the goal of determining the variability of the independently determined fluxes from each transect for the single-transect approach, and to compare with the results obtained from our multi-transect kriging method. The single-transect approach assumes that the measured pollutant plume components are uniformly mixed through the boundary layer in the vertical direction, i.e., that the observed incremental $\mathrm{CO}_{2}$ and $\mathrm{CH}_{4}$ concentrations in a given horizontal transect represent those at all altitudes within the boundary layer. This approach is also described by Eq. (1), except that the assumption of a well-mixed boundary layer effectively removes the need to interpolate the data. Using the observed pressure and temperature distributions from the vertical profile, the molar density of air as a function of altitude is calculated, and is subsequently integrated from the ground to the top of the boundary layer. To obtain the citywide flux, the integrated concentration enhancements are then multiplied by the mean perpendicular wind speed for each transect for $\mathrm{CO}_{2}$ or $\mathrm{CH}_{4}$, along the horizontal limits of the projected city boundary. Note that, for the case of the 1 June 2011 flight experiment, when the CBL depth grew $\sim 570 \mathrm{~m}$, we used the CBL 
depth halfway through the horizontal transects $(1720 \mathrm{~m})$ to be consistent with our method in the multi-transect kriging approach described in Sect. 2.5. We further note that the horizontal transects were of variable lengths, and that a transect was considered for single-transect flux calculation if its length covers the projected width of Marion County, which encompasses the bulk of Indianapolis.

\section{Results and discussion}

\subsection{Horizontal and temporal distribution of carbon dioxide and methane}

Our $\mathrm{CO}_{2}$ measurements are impacted by $\mathrm{CO}_{2}$ emissions and uptake from all sources, including fossil fuel $\mathrm{CO}_{2}$ and biological $\mathrm{CO}_{2}$ sources such as biomass burning, biofuel use, respiration, and photosynthesis. Fossil fuel $\mathrm{CO}_{2}\left(\mathrm{CO}_{2 \mathrm{ff}}\right)$ originates from a variety of sources, including energy usage related to residential, commercial, and industrial building operations; mobile source combustion within and around the city; and point sources, such as power generating stations and incinerators. $\mathrm{CH}_{4}$ is emitted from biogenic sources such as bacterial activity from landfills and wastewater treatment plants, and from anthropogenic sources such as leakage from natural gas infrastructure, and concentrated animal feeding operations (the latter of which do not exist in Indianapolis).

Figure 3 shows sample data for the temporal distributions of $\mathrm{CO}_{2}$ and $\mathrm{CH}_{4}$ along with altitude above ground for the 1 June 2011 experiment. In Fig. 3 we also indicate the CBL depths for the two vertical profiles flown during this experiment, indicating the $\sim 570 \mathrm{~m}$ increase in a $4 \mathrm{~h}$ time period (Supplement Table S2 and Fig. 2). We note that this considerable growth in boundary layer depth is consistent with the observed $\sim 3 \mathrm{~K}$ increase in surface temperature indicated by panels $\mathrm{c}$ and $\mathrm{d}$ in Fig. 2. This $570 \mathrm{~m}$ increase in the CBL depth is potentially a combination of the natural growth of the CBL and urban heat island (UHI) effects. We note that previous studies (Angevine et al., 2003; Trainer et al., 1995) have also reported an enhanced CBL depth downwind of urban environments. In a separate flight experiment on 30 June 2011, we flew a spiral ascent inside Indianapolis, followed by a spiral descent outside the city within a $30 \mathrm{~min}$ time interval (Supplement Fig. S9). The vertical profiles were flown above one INFLUX tower site located on the eastern side of Interstate 70 (urban site, downwind) and one above a forested area in Moorseville, IN (rural site, upwind), which is located southwest of Indianapolis. For this flight experiment, we observed (Supplement Fig. S9) a $\sim 200 \mathrm{~m}$ difference in boundary layer depths upwind and downwind the city, which may be potentially due to the UHI effect but may also be caused by variability in the typical turbulent structure of the CBL top. Thus, if this observed enhancement is primarily due to UHI, this particular day gives us a $\sim 10 \%$ difference in boundary depth between the city and rural sites. This result is

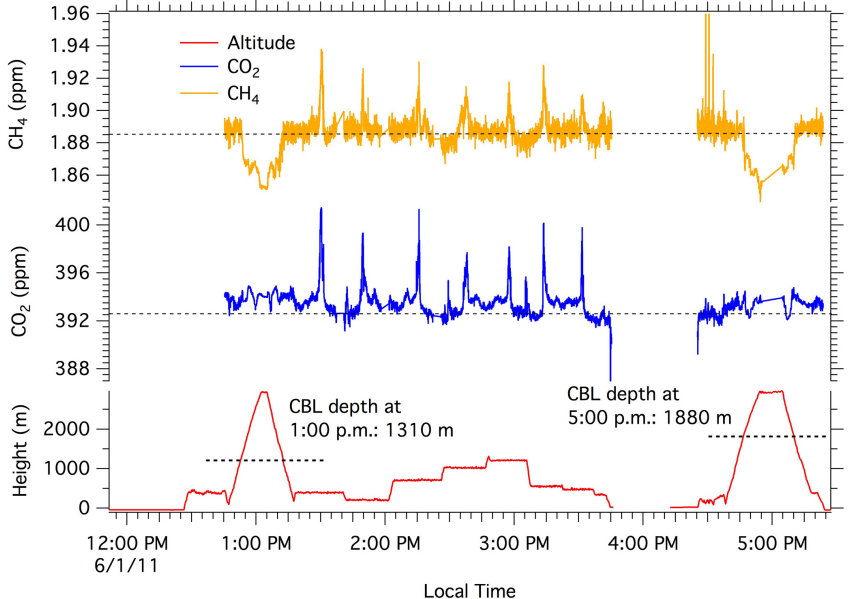

Figure 3. Temporal distribution of altitude (m a.g.1.), carbon dioxide, and methane on 1 June 2011. The broken lines in the $\mathrm{CO}_{2}$ and $\mathrm{CH}_{4}$ time series represent the mean background concentration averaged over all altitudes $(392.6 \pm 0.5 \mathrm{ppm}$ and $1880.6 \pm 2.6 \mathrm{ppb}$ for $\mathrm{CO}_{2}$ and $\mathrm{CH}_{4}$, respectively). Two vertical profiles were performed during this flight experiment, showing a $\sim 570 \mathrm{~m}$ growth in the boundary layer depth from the beginning of the experiment.

consistent with the observations of Angevine et al. (2003) for the city of Nashville, TN, where they observed a persistent summertime downwind heat island boundary layer enhancement of $160 \mathrm{~m}$, compared to mean boundary layer depths of 1 to $2 \mathrm{~km}$ (454 soundings from 10 June to 3 August 1999). Trainer et al. (1995) also observed a larger enhancement of $400 \mathrm{~m}$ downwind of Birmingham, AL, but from only one observed aircraft vertical profile. Our measurements and these two previous studies highlight the potential influence of the urban heat island enhancements on the CBL depth downwind of urban environments, and emphasize the importance of determining the CBL depth within the urban plume to minimize underestimation of the calculated flux. We accordingly conducted our vertical profiles downwind of the city for the three flight dates considered in these analyses (flight paths shown in Fig. 1 for the 1 June 2011 flight experiment, and in Fig. S4 in the Supplement for the 1 March and 29 April 2011 experiments).

We also observe in Fig. 3 the presence of temporally coherent elevated concentrations of $\mathrm{CO}_{2}$ and $\mathrm{CH}_{4}$, with enhancements up to $\sim 9 \mathrm{ppm}$ and $\sim 50 \mathrm{ppb}$ above the background, respectively. The large enhancements are colocated in space, as clearly seen in the horizontal and vertical distributions of observed and kriged $\mathrm{CO}_{2}$ and $\mathrm{CH}_{4}$ in Fig. 4. The $x$ axis in Fig. 4 represents the distance in kilometers of the flight track from an arbitrarily chosen center point on the horizontal transects. The projected city limits, and hence the limits of integration in the horizontal direction, were from $-35 \mathrm{~km}$ (shown by the white broken line in Fig. $4 \mathrm{c}$ and d) to $+45 \mathrm{~km}$. The horizontal transects for this experiment were just long enough to encompass the city width 
(A)
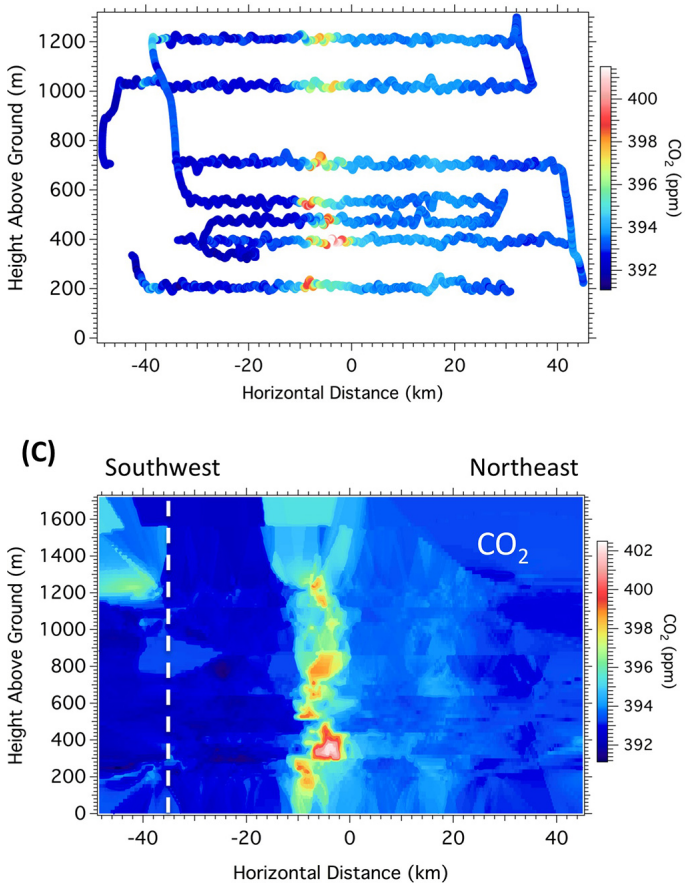

(B)

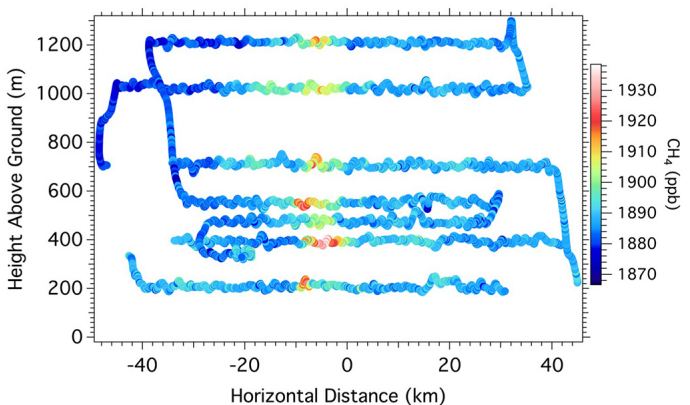

(10)

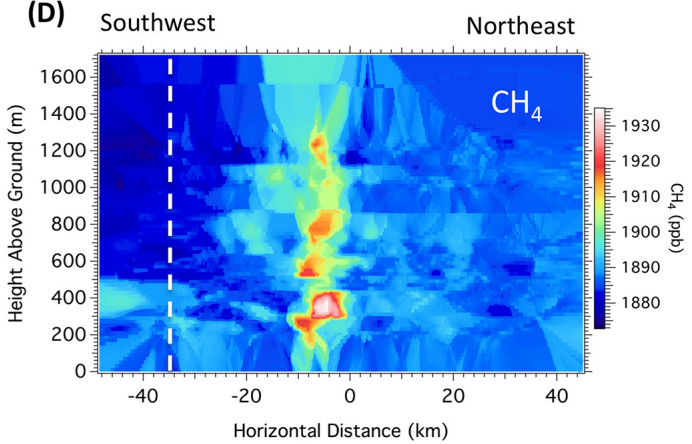

Figure 4. Horizontal and vertical distributions of (a) observed $\mathrm{CO}_{2}$, (b) observed $\mathrm{CH}_{4}$, (c) kriged $\mathrm{CO}_{2}$, and (d) kriged $\mathrm{CH}_{4}$ on $1 \mathrm{June} 2011$ corresponding to the transects in Fig. 1. The northeast end corresponds to positive distances while the southwest end corresponds to negative distances relative to the chosen center point. The projected city limits were from $-35 \mathrm{~km}$ (broken line) to $+45 \mathrm{~km}$. CBL depth was $1720 \mathrm{~m}$.

in the northeastern side (positive distance). Thus, the background $\mathrm{CO}_{2}$ and $\mathrm{CH}_{4}$ were taken from -48 to $-35 \mathrm{~km}$ (southwestern edge of the transect). Elevated $\mathrm{CO}_{2}$ concentrations outside the city boundary at the edges of the transects were also observed, and are attributed to the Eagle Valley power plant $\left(39.488^{\circ} \mathrm{N}, 86.415^{\circ} \mathrm{W}\right.$; Martinsville, IN). In a separate flight experiment on 8 February 2011, we detected the $\mathrm{CO}_{2}$ enhancement from the Eagle Valley power plant and followed the plume upwind to ascertain the source. These elevated concentrations do not flow into the city, and hence were not included in the determination of the background. For this case, $\mathrm{CO}_{2}$ concentrations outside the city boundary were attributed to the Eagle Valley power plant if they were at least 3 standard deviations greater than the rest of the background, and correlated by back trajectory analysis to the power plant. For the 1 June 2011 experiment, the background $\mathrm{CO}_{2}$ and $\mathrm{CH}_{4}$ (mean $\pm 1 s_{\mathrm{m}}$ ), assumed constant with height, were $392.6 \pm 0.5 \mathrm{ppm}$ and $1880.6 \pm 2.6 \mathrm{ppb}$ (black broken lines in Fig. 3), respectively, where $s_{\mathrm{m}}$ is the standard deviation of the mean at $95 \%$ CL determined using the sampling statistics described by Lenschow and Stankov (1986). Figure 4 shows that, in comparison to these numbers, the urban plume was captured downwind of the city, and that the observed enhancements were well above the variability of the background concentrations. We followed the source of the elevated concentrations $(\sim 9 \mathrm{ppm}$ and $\sim 50 \mathrm{ppb}$ enhance- ments mentioned above) downwind of the city during separate in-flight investigations and found that the largest $\mathrm{CO}_{2}$ and $\mathrm{CH}_{4}$ enhancements were originating from the Harding Street power generating facility and the Southside landfill and/or the natural gas transmission regulating station (TRS), respectively. These three sources are all situated on the southwest side of the city, with the landfill and TRS adjacently located, and separated by $\sim 1 \mathrm{~km}$ from the Harding Street power plant across the White River.

\subsection{Citywide $\mathrm{CO}_{2}$ and $\mathrm{CH}_{4}$ emissions}

Citywide $\mathrm{CO}_{2}$ and $\mathrm{CH}_{4}$ emissions are estimated using the mass balance approach on 3 days: 1 March, 29 April, and 1 June 2011. We note that the aircraft mass balance method determined the net flux out of the city. For all three flight days, we compare the total $\mathrm{CO}_{2}$ emission rate estimated using the mass balance approach to the Hestia bottom-up data for fossil fuel $\mathrm{CO}_{2}$, making the assumption that the measured $\mathrm{CO}_{2}$ is comprised solely of fossil fuel $\mathrm{CO}_{2}$ and there is no biogenic $\mathrm{CO}_{2}$ influence. The unpublished work of Turnbull et al. (2014), using $\Delta^{14} \mathrm{C}$ in $\mathrm{CO}_{2}$ to assess the fossil fuel component of the measured $\mathrm{CO}_{2}$, indicates that, in the winter (or non-growing seasons), $\mathrm{CO}_{2}$ enhancements are entirely fossil-derived for Indianapolis. Aircraft flask measurements of the fossil fuel $\mathrm{CO}_{2}$ content from the 29 April and 1 June flight experiments support this assumption, showing 
Table 1. Citywide $\mathrm{CO}_{2}$ and $\mathrm{CH}_{4}$ emissions estimated from the aircraft-based mass balance approach and the Hestia bottom-up method corresponding to the three flight dates. Total uncertainty in the Hestia county-level emissions is $(-15,+20 \%)$ at $95 \%$ confidence interval. Also shown are the Harding Street power plant (HSPP) $\mathrm{CO}_{2}$ emissions from the mass balance approach and EPA stack measurements, and the mass balance HSPP percentage contribution to the total citywide $\mathrm{CO}_{2}$ flux for the three flight dates. Uncertainty in the HSPP stack monitoring is $29 \%$.

\begin{tabular}{|c|c|c|c|c|c|c|}
\hline $\begin{array}{l}\text { Flight date } \\
\text { in } 2011\end{array}$ & $\begin{array}{r}\text { Total city } \mathrm{CO}_{2} \\
\text { emission rate } \\
\left(\mathrm{mol} \mathrm{s}^{-1}\right)\end{array}$ & $\begin{array}{r}\text { Hestia fossil } \mathrm{CO}_{2} \\
\text { emission rate } \\
\left(\mathrm{mol} \mathrm{s}^{-1}\right)\end{array}$ & $\begin{array}{r}\text { Total city } \mathrm{CH}_{4} \\
\text { emission rate } \\
\left(\mathrm{mol} \mathrm{s}^{-1}\right)\end{array}$ & $\begin{array}{r}\mathrm{HSPP} \mathrm{CO}_{2} \text { emission, } \\
\text { mass balance } \\
\left(\mathrm{mol} \mathrm{s}^{-1}\right)\end{array}$ & $\begin{array}{r}\mathrm{HSPP} \mathrm{CO}_{2} \\
\text { from EPA } \\
\left(\mathrm{mol} \mathrm{s}^{-1}\right)\end{array}$ & $\begin{array}{r}\text { \% HSPP } \\
\text { contribution } \\
\text { mass balance }\end{array}$ \\
\hline $1 \mathrm{March}$ & 11000 & 12122 & 93 & 5950 & 3589 & 54 \\
\hline 29 April & 7500 & 10751 & 101 & 5100 & 3871 & 68 \\
\hline 1 June & 26000 & 12134 & 197 & 10030 & 4407 & 39 \\
\hline
\end{tabular}

good correlations between enhancements in total and fossil fuel $\mathrm{CO}_{2}$ with slopes identical to unity within 2 standard deviations of the slope (Supplement Fig. S10). The city flask data (not taken downwind of the power plant plume, Supplement Fig. S10) for 29 April show a smaller slope (Supplement Fig. S10), suggesting possible uptake during this day. However, more radiocarbon data are needed for this month to ascertain that this is indeed the case. We also note that many of the flasks were sampled within the influence of the power plant plume where the fossil fuel component is larger and more dominant than over the larger urban area. Thus, more flask measurements within the urban plume (but outside the power plant plume) will be useful to examine the extent to which the estimated $\mathrm{CO}_{2}$ emission from the city of Indianapolis is strongly dominated by fossil fuel $\mathrm{CO}_{2}$, particularly during the summer growing season. While for 1 March there were no radiocarbon measurements from aircraft flask samples, analysis of tower-based flask samples shows that $\mathrm{CO}_{2}$ enhancements are entirely fossil-fuel-derived in this late winter period in Indianapolis (Turnbull et al., 2014). We note that for the growing season periods, biosphere exchange of $\mathrm{CO}_{2}$ represents a component of the measurement uncertainty, important to our comparison with the Hestia bottom-up data. In a companion paper (Turnbull et al., 2014), we discuss the partitioning of the urban $\mathrm{CO}_{2}$ enhancement into the fossil and biogenic components in detail. As discussed in that paper, measurements of the background $\mathrm{CO}_{2}$ at the "sides" of the city, simultaneous with the time of each transect, are likely optimum, for cases when the background has a diurnally varying character, due to biospheric impacts.

Calculated $\mathrm{CO}_{2}$ and $\mathrm{CH}_{4}$ emission fluxes for these dates are presented in Table 1 and Fig. 5. The estimated emissions (Table 1) were calculated using a vertically varying background for the three flight experiments. As mentioned above, we also calculated the flux using an average $\mathrm{CO}_{2}$ and $\mathrm{CH}_{4}$ background (Supplement Table S3) assumed to be constant with altitude and found a 3,14 , and $0.2 \%$ difference in the $\mathrm{CO}_{2}$ flux and a 3, 3, and $10 \%$ difference in the $\mathrm{CH}_{4}$ flux for the 1 March, 29 April, and 1 June experiments, respectively. As shown in Table 1, there is a 9 and $30 \%$ difference between

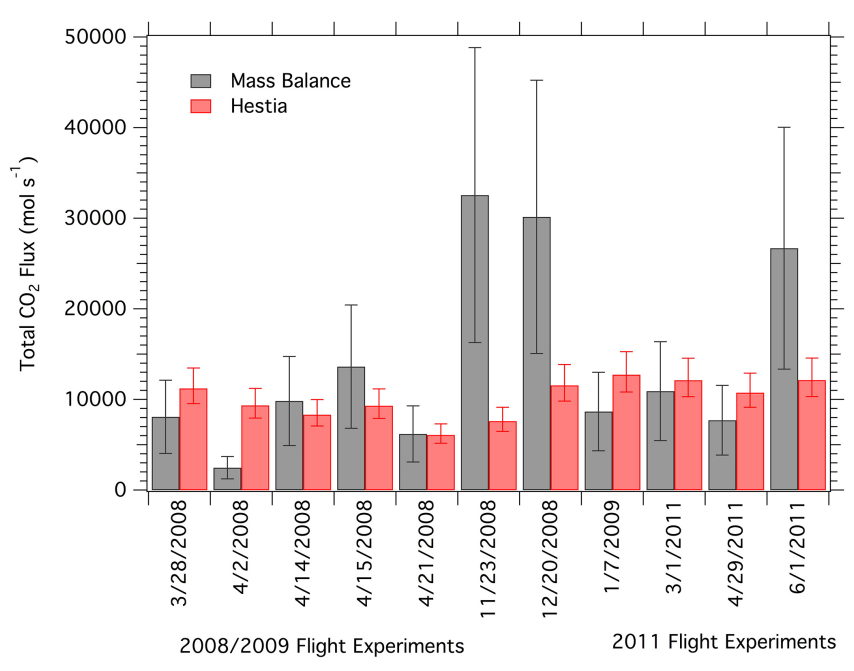

Figure 5. Indianapolis $\mathrm{CO}_{2}$ emissions for several flight experiments in 2008 and 2011 estimated from the aircraft-based mass balance and Hestia bottom-up approaches. Error bars in the mass balance approach represent our uncertainty estimate of $\pm 50 \%$, while the Hestia uncertainty is $(-15,+20 \%)$ at $95 \%$ confidence interval for Marion County.

the emissions estimated with the aircraft-based mass balance approach and the Hestia bottom-up method for 1 March and 29 April 2011, respectively. However, the measured citywide $\mathrm{CO}_{2}$ emission from observations was greater than the Hestia county estimate by a factor of $\sim 2.1$ for the 1 June 2011 experiment. For comparison, we include in Fig. 5 the Hestia emissions and aircraft-based mass balance measurements in Indianapolis for 2008 (Mays et al., 2009). Supplement Table $\mathrm{S} 4$ shows the $\mathrm{CO}_{2}$ emissions from the Hestia bottom-up approach and the aircraft-based mass balance measurements corresponding to the 2008 flight experiments (from Mays et al., 2009). We note that Mays et al. (2009) used the same multi-transect kriging method described above. The combined results from the 2008 and 2011 measurements show considerable day-to-day variability, which does not exist in the bottom-up emission data. When the $\mathrm{CO}_{2}$ fluxes were plotted against traffic flow data, Mays et al. (2009) showed 
that $\sim 57 \%$ of the variability in the citywide $\mathrm{CO}_{2}$ emission can be accounted for by mobile combustion sources. Except for city on-road $\mathrm{CO}_{2}$ emissions and $\mathrm{CO}_{2}$ emissions data from power generating facilities, which are measured and reported to the EPA, Hestia emission estimates rely on the temporally simulated average emission dynamics for the other sectors, which will vary based on hour of the day and day of the week. Hence, one-to-one agreement between the mass balance approach and the bottom-up emission estimate is not necessarily expected for specific hours within individual days. We also note that Hestia only accounts for the fossil fuel $\mathrm{CO}_{2}$, while our approach captures the total $\mathrm{CO}_{2}$ flux from the city. Thus, if the biological component is significant, our comparison may be biased.

We also report the methane flux from the city for the three flight experiments (Table 1) and note that there is also a considerable variability in the day-to-day emissions. This result may be due in part to the fact that one of the largest contributors to the total citywide methane emission is a landfill in the southwest side of the city, and its daily and seasonal emission is variable due to the dependence on temperature, pressure, and available moisture. The methane emission from Indianapolis and its apportionment to various sources is the subject of a separate manuscript (Cambaliza et al., 2014).

An important term in the budget of greenhouse gases in the atmospheric boundary layer (ABL) is entrainment from the free troposphere. Entrainment occurs as the boundary layer grows due to turbulence, and free-tropospheric air is entrained into the ABL. Detrainment (export of ABL air to the free troposphere) occurs (1) when there is horizontal inhomogeneity of mixing depths (e.g., urban-rural CBL depth contrast) (Angevine et al., 2003), (2) when convective turbulence dissipates at the end of the day, or (3) in the presence of convective clouds (e.g., thunderstorms). Our vertical profiles of $\mathrm{CO}_{2}$ and $\mathrm{CH}_{4}$ (Supplement Fig. S7) do not show any obvious evidence of measurable detrainment of CBL air into the free troposphere, most likely due to the proximity of our downwind flight path to the city plume. In addition, our measurements conclude by 16:00 LT, and thus do not include the evening collapse of the ABL. We have also not conducted measurements in the case of the presence of deep convective clouds. Thus, we assume that detrainment is not important for our experiments.

In our analyses, we account for entrainment by measuring the height of the boundary layer downwind of the city, and kriged the data to that height. In this situation, all of the entrainment that has occurred over the city has been accounted for in the measurement of outflow at the downwind edge of the city. This measurement approach, however, is still influenced by entrainment in that we assume that the background conditions that we measure at the "wings" of the urban plume are representative of both the boundary layer and free-tropospheric atmospheric conditions upwind of the city. If entrainment of free-tropospheric air is the same over the city as it is over the edges of the city, then the impacts of en-
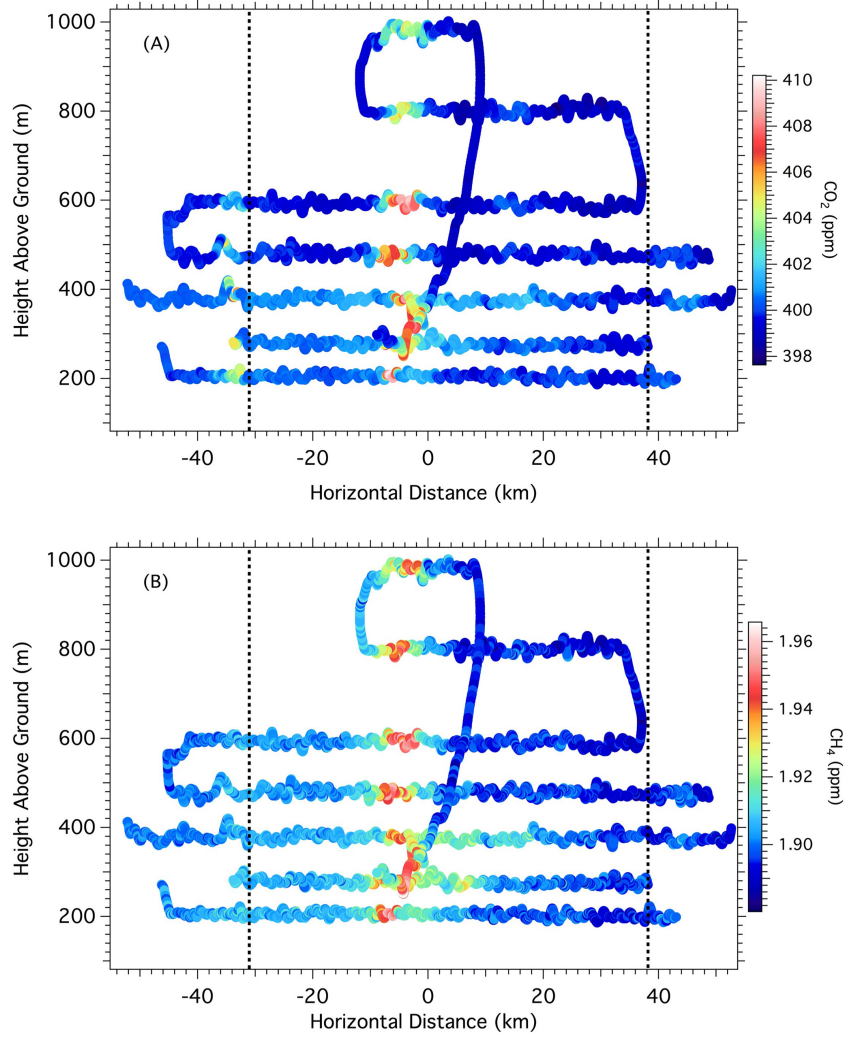

Figure 6. (a) $\mathrm{CO}_{2}$ and (b) $\mathrm{CH}_{4}$ observations on 29 April 2011 as a function of altitude and horizontal distance along the seven transects. Broken lines represent the projected city limits. CBL depth was $1110 \mathrm{~m}$.

trainment cancel in our calculation, and we assume this to be the case (Karion et al., 2013b).

\subsection{Sensitivity analyses}

In this section, we quantify the change in the $\mathrm{CO}_{2}$ and $\mathrm{CH}_{4}$ fluxes due to the uncertainties in the analysis parameters (Supplement Table S1). Table 2 summarizes the results from the sensitivity analyses for the 1 March, 29 April, and 1 June 2011 Indianapolis flight experiments. In our analyses it was not assumed, based on our measurements, that the boundary layer at the downwind observational plane was well mixed, i.e., that the observations from one horizontal transect are a representative sample of a uniform vertical composition for the entire boundary layer. For our flights, a typical distance to significant upwind point sources, e.g., the power plant, was $\sim 10 \mathrm{~km}$. For this distance, we typically observe considerable variability in the $\mathrm{CO}_{2}$ and $\mathrm{CH}_{4}$ concentrations in the vertical direction. This is evident, for example, in the $\mathrm{CO}_{2}$ and $\mathrm{CH}_{4}$ horizontal transect distributions for 29 April 2011 shown in Fig. 6. This figure shows enhancements from $\sim+4$ to $\sim+8 \mathrm{~km}$ for the $280 \mathrm{~m}$ and from $\sim+4$ to $+16 \mathrm{~km}$ for the $360 \mathrm{~m}$ transects, respectively, that are not observed in the other transects. For this sampling day for which the CBL 
Table 2. Percent change in (a) $\mathrm{CO}_{2}$ and (b) $\mathrm{CH}_{4}$ emission rate as a function of the uncertainties in analysis parameters for three Indianapolis flight dates in 2011.

\begin{tabular}{lrrrr}
\hline (a) $\mathrm{CO}_{2}$ flux sensitivity & & & & \\
\hline & 1 March & 29 April & 1 June & Average \\
\hline Background & 13 & 18 & 31 & $21 \pm 9$ \\
CBL depth & 32 & 22 & 14 & $23 \pm 9$ \\
Perpendicular wind speed & 12 & 20 & 14 & $15 \pm 4$ \\
Interpolation method & 0.2 & 28 & 9 & $12 \pm 14$ \\
Urban heat island dilution of background & 57 & 22 & 6 & $28 \pm 26$ \\
Surface extrapolation effect & 24 & 8 & 7 & $13 \pm 10$
\end{tabular}

(b) $\mathrm{CH}_{4}$ flux sensitivity

\begin{tabular}{lrrrr}
\hline & 1 March & 29 April & 1 June & Average \\
\hline Background & 8 & 23 & 32 & $21 \pm 12$ \\
CBL depth & 35 & 13 & 8 & $19 \pm 14$ \\
Perpendicular wind speed & 12 & 21 & 17 & $17 \pm 5$ \\
Interpolation method & 6 & 12 & 7 & $8 \pm 3$ \\
Urban heat island dilution of background & 57 & 35 & 23 & $38 \pm 17$ \\
Surface extrapolation effect & 9 & 16 & 4 & $10 \pm 6$ \\
\hline
\end{tabular}

depth is $1100 \mathrm{~m}$, the characteristic timescale for air to cycle once from the bottom to the top of the CBL (Stull, 1997) is $\sim 10 \mathrm{~min}$, where the calculated convective velocity scale is $\sim 1.9 \mathrm{~m} \mathrm{~s}^{-1}$. The corresponding horizontal length scale for this one cycle time is $\sim 2.4 \mathrm{~km}$ given that the mean wind speed for this day was $\sim 4 \mathrm{~ms}^{-1}$. A typical sampling distance of $10 \mathrm{~km}$ from the power generating station is approximately 4 times longer than the $2.4 \mathrm{~km}$ length scale. This sampling distance may be sufficient to achieve well-mixed conditions for this point source, but the city covers a large area with distributed sources that may be located closer to the horizontal transects. Thus, multiple horizontal transects at various altitudes within the stationarity time constraints (i.e., time intervals in which it is safe to assume unchanging fluxes, CBL depths, and winds) are important for accurate sampling of source-specific features. However, it is not possible to sample very close to the ground, and sometimes not possible to sample all the way to the top of the boundary layer; in addition, the vertical spacing between the horizontal transects may be appreciable. For these reasons, there is significant uncertainty resulting from the interpolation procedure (Table 2).

The CBL depths used for the calculations were 525, 1110 , and $1720 \mathrm{~m}$, while the standard deviations of $z_{i}$ at the $95 \%$ CL were 75, 140, and $204 \mathrm{~m}$ for 1 March, 29 April, and 1 June, respectively. Thus, we evaluated the change in the flux corresponding to a relative increase in the CBL depths of 14,13 , and $12 \%$ for the three flight dates. The corresponding average change in the flux for the three flight dates was 23 and $19 \%$ for $\mathrm{CO}_{2}$ and $\mathrm{CH}_{4}$, respectively, with the largest change in the flux for the 1 March flight experiment (Table 2). This significant uncertainty is expected in part because the
CBL depth increased without a corresponding increase in measurement transects to constrain the interpolation of the data up to the new CBL depth. Thus, had the transects been flown, the uncertainty would likely have been smaller.

Because of our inability to fly close to the ground, the absence of data between the lowest altitude transect and the surface also contributes to the uncertainty estimates. As stated above, we have observed the greenhouse gas enhancements to be often heterogeneously distributed in the vertical, given the proximity of our downwind measurements to the city sources. Thus, we considered the extreme cases, where we assumed that the city plume is not observed in a hypothetical transect between the ground and the lowest altitude measurement, as well as the case where we assumed that the mole fractions in the hypothetical transect are the same as for the lowest observed transect data. The latter approach results in a small average change of 5 and $3 \%$ for $\mathrm{CO}_{2}$ and $\mathrm{CH}_{4}$, respectively, for the three flight dates. As expected, we find that the surface extrapolation effect (Table 2) was more pronounced for the extreme case, where we assigned background mole fractions in the hypothetical transect. In this case, the change in flux (Table 2) yielded an average of 13 and $10 \%$ for $\mathrm{CO}_{2}$ and $\mathrm{CH}_{4}$, respectively, for the three flight experiments, which we assume is the upper limit impact.

We determined the influence of the observed uncertainty in the perpendicular wind speed to the estimated emission, and found that changing the magnitude of the perpendicular wind speed by the overall uncertainty $\left(\sim 0.7 \mathrm{~m} \mathrm{~s}^{-1}\right)$, given the observed variability and the method uncertainty, yielded identical results for both the $\mathrm{CO}_{2}$ and $\mathrm{CH}_{4}$ fluxes (an average of 15 and $17 \%$ change in the flux for $\mathrm{CO}_{2}$ and $\mathrm{CH}_{4}$, respectively, at the $95 \% \mathrm{CL}$, as shown in Table 2). The aircraft measures 
the winds continuously throughout the course of the experiment, and these changing mean winds were used in the flux calculations, thereby minimizing the uncertainty in the flux due to this component, and we do not include this component in the estimated overall uncertainty. We note that, in addition to the impact of the wind variability on flux values, the history of the horizontal winds prior to the experiment can also be important in the mass balance approach. The presence of sustained, steady winds ensures that the integrated mass flux through the measurement plane at the time of measurement is essentially equal to the total mass flux from the source at the time of emission. The mean horizontal wind speeds were $5.8,4.0$, and $5.9 \mathrm{~m} \mathrm{~s}^{-1}$ (averaged over all altitudes) for the 1 March, 29 April, and 1 June 2011 experiments, respectively. If the emissions from the city mix with an air mass traveling across Indianapolis with the observed wind speeds $(\sim 6$ and $4 \mathrm{~m} \mathrm{~s}^{-1}$ ), this air mass will pass from the city (taken to be $\sim 70 \mathrm{~km}$ wide) center to the point of interception in $\sim 1.5$ to $2.5 \mathrm{~h}$. This is then the required corresponding time frame for constant wind speeds for a city of this size.

We calculated the variability in the gridded background concentrations at each $20 \mathrm{~m}$ altitude bin and determined the uncertainty introduced in the flux, as described above. On average, we obtained a change in the flux of $21 \%$ for both $\mathrm{CO}_{2}$ and $\mathrm{CH}_{4}$ (Table 2). It is important to note that the uncertainty in the flux due to the background depends significantly on the magnitude of the enhancements. For large source strengths, such as power plants and landfills (e.g., Harding Street power plant and Southside landfill), the plume is clearly defined and easily detectable above background. Conversely, uncertainty in the background becomes more important for sources with smaller incremental enhancements (e.g., the distributed mobile source sector) above the background.

Given our procedure for acquisition of background data, the aircraft-based approach is sensitive to incremental enhancements from sources that are directly upwind of the city. Thus, sampling of the air mass concentrations directly upwind of the city across its horizontal width could help quantify the impact of direct upwind sources. Future use of both upwind aircraft-based measurements and ground-based measurements from upwind towers will also help reduce the impact of background concentration uncertainty.

As mentioned in the methods section, we conducted our vertical profiles downwind of the city. This, therefore, accounts for possible heat island enhancement in the urban CBL depth. We note that the UHI effect may potentially lead to a difference in the entrainment rate between the urban plume and the edges of the city (where background is taken), from horizontal heterogeneity in the CBL depth (e.g., higher CBL depth inside the city plume relative to the edges). It is then possible that the inflow of background air into the city will encounter a deeper CBL. Thus, there is an additional component in the uncertainty associated with the dilution of the background due to UHI enhancement in the CBL depth. We therefore calculate the change in the emission flux due to a change in the background assuming a $10 \%$ increase in the CBL depth, a figure that is based on our measurement from 30 June 2011, as well as on the observations of Angevine et al. (2003). We used the measured mean $\mathrm{CO}_{2}$ and $\mathrm{CH}_{4}$ free-tropospheric molar ratios obtained from the vertical profiles (Supplement Fig. S7) for the three flight experiments to calculate the change in the background molar ratios due to entrainment. This sensitivity analysis is therefore also a measure of the effect of entrainment on the estimated emissions. On average, we find that a calculated $0.4 \mathrm{ppm}$ change in background $\mathrm{CO}_{2}$ yields a $28 \%$ change in $\mathrm{CO}_{2}$ emission (Table 2, and Table S5 in the Supplement), while a mean $4.4 \mathrm{ppb}$ change in background $\mathrm{CH}_{4}$ results in a $38 \%$ change in $\mathrm{CH}_{4}$ flux. These results further express the substantial impact uncertainty in the background concentration can have on the calculated emission rate.

We note that the sensitivity analyses discussed here do not necessarily capture all parameters influencing the accuracy of the flux determination. The interpolated $\mathrm{CO}_{2}$ and $\mathrm{CH}_{4}$ plumes in Fig. 4, for example, are not the result of a frozen concentration field; that is, they are observed images of the $\mathrm{CO}_{2}$ and $\mathrm{CH}_{4}$ plumes that will move spatially over a $3 \mathrm{~h}$ time period, the approximate duration of one flight experiment. This problem is amplified when the sampling distance is close to the source and not achieving well-mixed conditions. On the other hand, the impact of the background subtraction is smaller with a larger detected enhancement, reflecting a trade-off in errors. Thus, a component of the overall uncertainty not directly probed here is the impact of non-stationary plumes on the interpolation. Indirectly, this is reflected in the assessment of precision, as discussed below. However, the analysis presented here provides insights on procedures to improve the experimental approach, as discussed in the Conclusions. We note that these sensitivity calculations inform us about components of the experiment that can be improved. However, components such as heat island impacts are not direct components of the computation, and thus an explicit propagation of errors to include all variables to which the result is sensitive is not feasible. The combined effect is, however, reflected in the precision measurements, as discussed in the next section.

\subsection{Evaluation of method precision using measurements from multiple downwind distances}

Here we discuss the results from four flight experiments that were designed to determine the precision of the approach. Using the multi-transect kriging approach, we calculated the flux from two or more downwind distances and quantified the difference in the flux estimates as a measure of the method precision. 

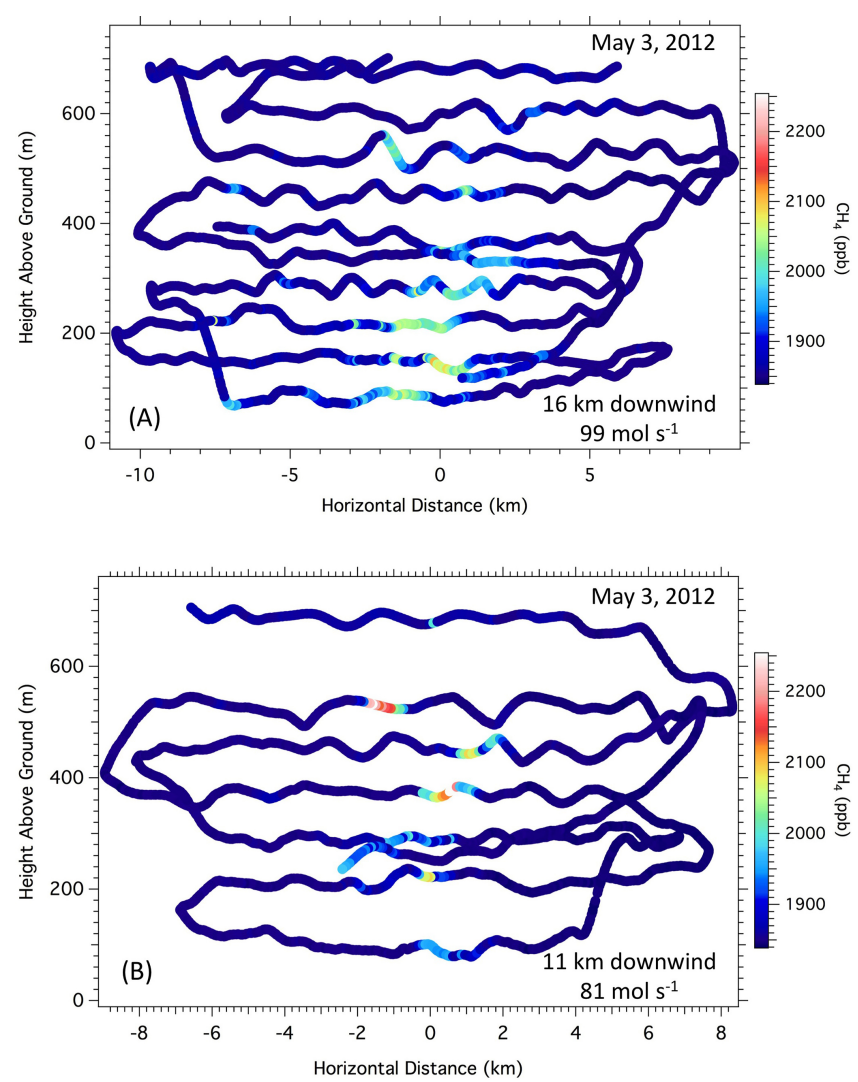

Figure 7. Observed methane concentrations for the 3 May 2012 Newton County landfill flight experiment for two downwind distances: (a) $16 \mathrm{~km}$ and (b) $11 \mathrm{~km}$. Vertical profiles were flown after the 16 and $11 \mathrm{~km}$ horizontal transects, showing CBL depths of 700 and $840 \mathrm{~m}$, respectively.

\subsubsection{Newton County landfill experiments}

Two flight experiments were conducted downwind of the Newton County landfill. Supplement Fig. S8 shows the flight paths for the 16 June 2011 and 3 May 2012 experiments. During the 16 June experiments, winds were from the west, with an average magnitude of $8 \mathrm{~m} \mathrm{~s}^{-1}$, and measurements were conducted at two downwind distances (5 and $11 \mathrm{~km}$ ). On 3 May 2012, winds were from the southwest, with an average magnitude of $11 \mathrm{~m} \mathrm{~s}^{-} 1$, and measurements were conducted at 11 and $16 \mathrm{~km}$ downwind distances. For the latter flight date, the horizontal transect measurements $16 \mathrm{~km}$ from the main source were also intercepting the plume of 7 dairy farms that were downwind of the landfill. These dairy farms were located between 11 and $16 \mathrm{~km}$ downwind of the landfill, and hence did not impact the $11 \mathrm{~km}$ horizontal transect measurements (Supplement Fig. S8). A list of confined animal feeding operations in Indiana (http://www.in.gov/idem/ 4994.htm, accessed 6 September 2012) shows that, in 2012, there were a total of 29060 cattle and 6200 calves from the 7 dairy farms, from which we can estimate emissions.
In Fig. 7, we show the measured methane concentrations from the Newton County landfill experiments for the 3 May 2012 measurement. We observed significant enhancements within the methane plume downwind of the landfill. The $\mathrm{CH}_{4}$ background was $1850 \pm 2 \mathrm{ppb}$, while the enhancements were at least $100 \mathrm{ppb}$, but in some cases up to $400 \mathrm{ppb}$ above the background. Because the ratio of the uncertainty in the background to the enhancement is small $(\leq \sim 2 \%)$, the total uncertainty is minimized, and the plume is clearly defined, which then makes the comparison of the results for the two distances idealized. In this experiment, we note again that the observed methane plumes were not uniformly distributed in the vertical direction, and a well-mixed boundary layer could not be assumed.

Table 3 shows the estimated fluxes for the two Newton County landfill experiments and the percentage difference between fluxes for the two downwind distances. Because we were intercepting the plume from seven dairy farms during the 3 May 2012 experiment at $16 \mathrm{~km}$ distance downwind, we accounted for the contribution from a total of 35260 dairy cattle and calves and subtracted their calculated emission from the total observed flux. We used emission factors derived from a tracer technique in the literature (Johnson et al., 1994; Westberg et al., 2001) to obtain the methane flux contribution from the dairy farms. Observed variability in repeated measurements over 5 days using the tracer technique was $\pm 30 \%$ (Johnson et al., 1994). The total estimated emission flux from the $16 \mathrm{~km}$ downwind distance was $108 \mathrm{~mol} \mathrm{~s}^{-1}$, while the calculated methane flux from the dairy farms was $9 \mathrm{~mol} \mathrm{~s}^{-1}$. The difference $\left(99 \mathrm{~mol} \mathrm{~s}^{-1}\right)$ is the net emission from the landfill (Table 3). Based on the results shown in Table 3, the percentage differences in the methane fluxes for the two distances for the 16 June 2011 and 3 May 2012 experiments were 39 and $20 \%$, respectively.

\subsubsection{Twin Bridges landfill experiment}

On 30 August 2012, we sampled the methane plume from the Twin Bridges landfill using two sets of horizontal transects at 3 and $6 \mathrm{~km}$ downwind distances (Supplement Fig. S8). Winds were from the southeast, with an average magnitude of $5 \mathrm{~m} \mathrm{~s}^{-1}$. Similar to the observations from the Newton County landfill experiments, the measured methane horizontal distributions from the Twin Bridges landfill show the plume to be clearly defined above the background with average enhancements of $\sim 150 \mathrm{ppb}$ for the two downwind distances. We find that the methane fluxes were 16 and $18 \mathrm{~mol} \mathrm{~s}^{-1}$, corresponding to the 3 and $6 \mathrm{~km}$ downwind distances (Table 3), respectively. These results represent, on average, a $\sim 12 \%$ difference between the estimated fluxes.

\subsubsection{Harding Street power plant experiment}

The Harding Street power generating station has a stack height of $172 \mathrm{~m}$, and emits thermally buoyant plumes into 
Table 3. Percentage difference between estimated emission rate from two or more downwind distances for four flight experiments.

\begin{tabular}{lrrr}
\hline Flight date and experiment & $\begin{array}{r}\text { Downwind distance } \\
(\mathrm{km})\end{array}$ & $\begin{array}{r}\text { Emission rate } \\
\left(\mathrm{mol} \mathrm{s}^{-1}\right)\end{array}$ & $\begin{array}{r}\text { Difference } \\
(\%)\end{array}$ \\
\hline 16 June 2011, Newton Co. landfill $\left(\mathrm{CH}_{4}\right)$ & 5 & 56 & 39 \\
& 11 & 83 & 20 \\
\hline 3 May 2012, Newton Co. landfill $\left(\mathrm{CH}_{4}\right)$ & 11 & 81 & 12 \\
\hline 30 August 2012, Twin Bridges landfill $\left(\mathrm{CH}_{4}\right)$ & 16 & 99 & \\
& 3 & 16 & \\
\hline 1 June 2012, Harding St. power plant $\left(\mathrm{CO}_{2}\right)$ & 6 & 1350 & $52^{*}$ \\
\end{tabular}

* Derived from the standard deviation of the resulting $\mathrm{CO}_{2}$ emission fluxes from the three downwind distances divided by the mean.

the atmosphere. Unlike the surface emissions from the mobile combustion sources, we expect the power plant plume to rise through the boundary layer up to the capping inversion, and then mix through the CBL at some distance downwind. Three sets of horizontal transects were conducted in rapid succession downwind of the Harding Street power plant on 1 June 2012 at 5, 8, and $17 \mathrm{~km}$ (Supplement Fig. S8). The winds were from the northwest, with an average magnitude of $\sim 10 \mathrm{~m} \mathrm{~s}^{-1}$. This sampling day was characterized by a dense overcast layer at the boundary layer top, and relatively high winds. During such days when aircraft vertical profiles through the top of the boundary layer are not possible (to protect the BAT probe), the depth of the boundary layer was estimated from the observed cloud-base altitude (640 m a.g.l.). Table 3 shows the calculated fluxes from the three downwind distances. The average $\mathrm{CO}_{2}$ flux from the three sets of transects was $1530 \pm 790 \mathrm{~mol} \mathrm{~s}^{-1}$, yielding a (1 standard deviation) precision of $52 \%$. Thus, based on the summary shown in Table 3, the lower and upper bounds of the precision determinations, for point sources, were 12 and $52 \%$. The average of the values in Table 3, 30\%, represents the precision for point sources. However, as stated above, this value minimizes the impact of uncertainty in the background, while the other components in Table 2 are represented in the precision experiments. If we combine the observed average precision with the impact of the background uncertainty, we calculate an overall uncertainty of $37 \%$. To include the impact of other but unknown systematic errors, we assume for the discussion below a conservative overall method uncertainty of $\pm 50 \%$.

Ideally, under steady conditions (e.g., steady, sustained winds and boundary layer depth, and constant emission from the source), the emission fluxes calculated from measurements at multiple downwind distances are essentially identical. Thus, the variability in the observed emission fluxes effectively quantifies the combined influences of various variables (interpolation errors, sampling statistics, and instrumental limitations) that may affect the magnitude of the mea- sured fluxes, and is therefore a measure of the method precision. We can compare these results, which are at the low end of those reported by previous studies that made use of an aircraft-based mass balance approach to estimate emissions from an urban plume or an area-wide source for different trace gases: $20 \%$ for $\mathrm{CO}$ and $40 \%$ for $\mathrm{NO}_{\mathrm{x}}$ emissions from Augsburg, Germany (Kalthoff et al., 2002); $50 \%$ for $\mathrm{CH}_{4}$ from a pastoral farming region in New Zealand (Wratt et al., 2001); $50 \%$ for $\mathrm{CH}_{4}$ from dairy farms in the South Coast Air Basin, CA, USA (Peischl et al., 2013); $100 \%$ for $\mathrm{CO}_{2}$ from Sacramento, CA, USA (Turnbull et al., 2011); and $100 \%$ for $\mathrm{NO}_{\mathrm{x}}$ emission measurements from Birmingham, $\mathrm{AL}$, USA (Trainer et al., 1995). In these previous studies, main sources of uncertainties in emission estimates were attributed to uncertainties in concentration measurements (Wratt et al., 2001), and variability of horizontal wind speeds (Trainer et al., 1995; Turnbull et al., 2011).

Figure 8 shows the 1 June $2012 \mathrm{CO}_{2}$ emissions from the Harding Street power plant estimated using the mass balance approach and those reported from stack measurements (EPA Air Markets Program Data: http://ampd.epa.gov/ampd/, accessed August 2012). For comparison, the $\mathrm{HSPP} \mathrm{CO}_{2}$ measured and reported emissions for 1 March, 29 April, and 1 June 2011 were also included (Fig. 8 and Table 1). To isolate the HSPP contribution from the total city emission, we assume that the plume cells are attributable to HSPP if the concentration is at least 2 standard deviations greater than the mean city concentration and that the back trajectory from the point of observation intersects with the power plant. Error bars in the mass balance approach represent a conservative $50 \%$ estimate, consistent with the relative uncertainty observed in the flux estimates from the three downwind distances during the 1 June 2012 HSPP experiment. The uncertainty in the reported stack measurements is estimated to be $29 \%$, which represents the standard deviation of the bias-corrected distribution of differences between the EPA CAMD and EIA (Energy Information Administration) data 


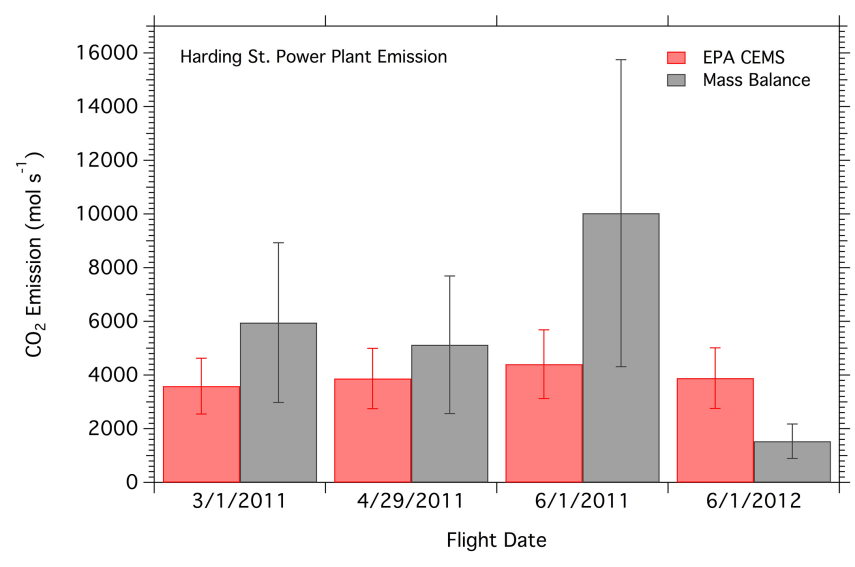

Figure 8. Harding Street power plant $\mathrm{CO}_{2}$ emission estimates from the mass balance and EPA CEMS monitoring approaches. Error bars in the CEMS monitoring represent a $29 \%$ uncertainty while error bars in the mass balance approach correspond to the $50 \%$ uncertainty estimate.

on a monthly/yearly level for all power plant facilities in the United States. We observed that the emissions from the two approaches were not statistically significantly different for the 2011 flight experiments within the estimated uncertainties. However, the observed $\mathrm{CO}_{2}$ flux on 1 June 2012 was $60 \%$ smaller than reported by EPA. It is possible that the aircraft-based approach under-sampled the plume on this flight date because visual flight rules require that aircraft fly at least $150 \mathrm{~m}$ below the cloud cover. Nevertheless, it is possible to determine from this set of observations the contribution of the HSPP to the total citywide $\mathrm{CO}_{2}$ flux. In Table 1, we summarize the isolated HSPP and citywide $\mathrm{CO}_{2}$ emissions and determine from observations that the $\mathrm{HSPP} \mathrm{CO}_{2}$ flux accounts for $\sim 54 \%$ of the $\mathrm{CO}_{2}$ emissions from the city, on average, for three afternoons in 2011. This result is larger than the findings ( $37 \%$ ) of Mays et al. (2009). For comparison, Gurney et al. (2012) estimate a $28 \%$ contribution from HSPP using the bottom-up approach for year 2002. Using the results from the $\mathrm{HSPP} \mathrm{CO}_{2}$ emission rate determined from the continuous stack monitoring for the 3 days considered in the analyses (Table 1), the HSPP $\mathrm{CO}_{2}$ emissions contribute $34 \%$ on average compared to the total citywide Hestia estimated flux (Table 1). We note that the emission from HSPP is not constant (Gurney et al., 2012). Gurney et al. (2012) found that relative to the other eight townships in Indianapolis, Decatur Township, where the Harding Street power generating facility is located, has considerable variability in its fossil fuel $\mathrm{CO}_{2}$ emissions that reflect the electricity production variations of HSPP.

\subsection{Evaluation of the single-transect mass balance method}

We revisited the 1 March, 29 April, and 1 June 2011 Indianapolis flight experiments and recalculated the fluxes using the single-transect mass balance method. Several aircraftbased mass balance studies conducted to date have utilized a single-transect approach that assumes a uniformly mixed boundary layer for the enhancements (Karion et al., 2013b; Peischl et al., 2013; Turnbull et al., 2011; Trainer et al., 1995; White et al., 1983). To evaluate the relative viability of such an approach, enabling more rapid flux measurements, we calculated the $\mathrm{CO}_{2}$ and $\mathrm{CH}_{4}$ emission fluxes using observations from each transect in our experiment days to obtain multiple independent estimates of the citywide flux for the $1 \mathrm{March}$, 29 April, and 1 June 2011 flight experiments. Table 4 shows the total number of transects sampled for each of the three flight dates as well as the number of usable transects for the single-transect calculations. To remove biases arising from the background, we used the mean of the background concentrations from the edges of the interpolated data (outside the city limits) corresponding to the altitudes of the individual transects. This approach is chosen since, when implementing a single-transect approach, one would design a flight plan to ensure that adequate background data were acquired to support each sample transect. The perpendicular wind speed used in the calculation was the average wind speed normal to each transect. Table 4 shows the mean $\mathrm{CO}_{2}$ and $\mathrm{CH}_{4}$ emission fluxes for the three flight dates estimated using the single-transect approach together with the relative standard deviation, which reflects the precision of the assumption that any given transect represents the full boundary layer in the vertical scale. For the case of the 1 March flight experiment, we present the percentage difference of the flux estimates from two transects. Supplement Table S6 shows all of the independently determined values of the $\mathrm{CO}_{2}$ and $\mathrm{CH}_{4}$ fluxes for the three flight dates. For comparison, Table 4 also shows the results from the multi-transect kriging method (also shown in Table 1). Precision for the multi-transect kriging method was taken as $30 \%$ based on the average variability observed from the multiple downwind distance experiments (discussed in the previous section). We note that the precision for our multi-transect kriging method may be larger than this, given the larger scale and smaller incremental concentrations that apply to the urban-scale measurements. We find that the estimated fluxes from the two approaches are not statistically significantly different if we compare the mean from the single-transect approach. However, many of the individual determinations via the single-transect approach (i.e., the way it would be implemented) would be significantly different from the multi-transect result. The variability of the determined emission rates from the single-transect approach ranges from 23 to $65 \%$. In Fig. 6 we have shown the $\mathrm{CO}_{2}$ and $\mathrm{CH}_{4}$ observations for the seven transects on 29 April 2011, for which we calculated a standard deviation of 51 and $58 \%$ 
Table 4. Citywide $\mathrm{CO}_{2}$ and $\mathrm{CH}_{4}$ emission fluxes $\left(\mathrm{mol} \mathrm{s}^{-1}\right.$ ) derived from the single-transect method (mean $\left.\pm 1 \mathrm{~s}\right)$ and via the multi-transect kriging approach for the three flight dates in 2011. Percentage values in parentheses represent the relative standard deviation. The stated precision in the multi-transect kriging approach is $30 \%$, with the average precision obtained from the multiple downwind experiments (Table 3).

\begin{tabular}{lll|ll|ll}
\hline $\begin{array}{l}\text { Flight date } \\
\text { in 2011 }\end{array}$ & $\begin{array}{l}\text { Total no. } \\
\text { of transects }\end{array}$ & $\begin{array}{l}\text { No. of usable } \\
\text { transects }\end{array}$ & \multicolumn{2}{|c|}{ Single-transect method } & \multicolumn{2}{|c}{ Multi-transect kriging approach } \\
\hline & & & $\mathrm{CO}_{2}$ flux & $\mathrm{CH}_{4}$ flux & $\mathrm{CO}_{2}$ flux & $\mathrm{CH}_{4}$ flux \\
\hline 1 March & 4 & 2 & $\begin{array}{l}12800 \\
(17000,8700)^{1} \\
(65 \%)^{2}\end{array}$ & $\begin{array}{l}130 \\
(170,85)^{1} \\
(65 \%)^{2}\end{array}$ & $11000 \pm 3300$ & $93 \pm 28$ \\
& & & $\begin{array}{l}8950 \pm 4600 \\
(51 \%)\end{array}$ & $\begin{array}{l}105 \pm 60 \\
(58 \%)\end{array}$ & $7500 \pm 2250$ & $101 \pm 30$ \\
\hline 29 April & 7 & 5 & $24000 \pm 5500(23 \%)$ & $\begin{array}{l}190 \pm 79 \\
(42 \%)\end{array}$ & $26000 \pm 7800$ & $197 \pm 59$ \\
\hline 1 June & 7 & 5 & & & & \\
\hline
\end{tabular}

1 Values of the flux estimates from the two individual transects.

2 Represents the percentage difference between the flux estimates from the two individual transects.

for $\mathrm{CO}_{2}$ and $\mathrm{CH}_{4}$ emission rates for the single-transect approach, respectively. The broken lines represent the limits of integration in the horizontal direction corresponding to the city boundary. Based on the observed significant variability in the measured concentrations for the various transects as a function of altitude, it is not unexpected that the independently determined fluxes were also highly variable. In Fig. 4 and Supplement Fig. S11 we show the corresponding horizontal transect observations for the 1 June and 1 March 2011 flight experiments, respectively. We note the strong methane signal measured in one horizontal transect but not observed in the other transects during the 1 March flight experiment (Supplement Fig. S11). The result from this investigation indicates that the boundary layer is not always uniformly distributed during sampling. Our results indicated that to enable reliable uncertainty determinations, one would generally need to prove, through measurements in each case, that the boundary layer is well mixed. However, doing so would then effectively remove the time-saving benefits of the singletransect approach.

\section{Conclusions}

This research involved assessment of important variables contributing to the uncertainty of an aircraft-based mass balance approach. This uncertainty analysis is dependent on the approach, for example on the method for acquiring background data, the number of transects, the distance from the sources, etc. The aircraft-based mass balance approach is an attractive method for quantifying emissions from both citywide and area-wide sources because of its inherent ability to cover the entire footprint of the source and its capability to determine the state of the boundary layer during measurement. Optimization of the experimental design is impor- tant, and one of the primary objectives of INFLUX. We suggest the following improvements in the method based on this study. Measurement performance improvements can be realized by (1) carefully determining the background $\mathrm{CO}_{2}$ and $\mathrm{CH}_{4}$ concentrations from the edges of the downwind transects, (2) monitoring the dynamics of the convective boundary layer, (3) increasing the number of downwind horizontal transect measurements, and (4) conducting low approach measurements in the downwind plume. An upwind horizontal transect in the middle of the boundary layer to ascertain the presence of plumes from direct upwind sources and correction of the fluxes in such cases is essential. We find that the use of the upwind transect for background concentration determination is not viable. This results from the fact that the transit time for air across the city is on the order of 3-4 h. The actual background air for the downwind transects would then need to be measured upwind at 09:00-10:00, which is not practical, since the boundary layer height is very low at that time, and the boundary layer is often relatively stable, meaning that concentrations measured aloft can be quite disconnected from the surface. Our method could be further improved with two aircraft operating simultaneously in order to increase the downwind sample (and background) coverage and decrease the elapsed time for the experiment. Alternatively, a single higher speed aircraft can perform the upwind and downwind transects and might provide the same advantage as two aircraft.

A second component of the uncertainty in the estimated flux arises from uncertainty in boundary layer height. Thus a vertical profile obtained before and after the experiment would help monitor the dynamics of the CBL. As we have done in our experiments, we also recommend that aircraft vertical profiles be conducted on the downwind side to evaluate and account for possible boundary layer enhancements 
caused by UHI effects (Trainer et al., 1995; Angevine et al., 2003), thereby minimizing uncertainties in the calculated flux. Alternatively, continuous remotely sensed measurements of the CBL depth within the city such as those obtained from lidar backscatter profiles would also help better constrain the growth or decay of the boundary layer during the course of the experiment, thereby improving the overall uncertainties. A wind lidar instrument is now installed and currently operating in Indianapolis, and provides vertical profiles of horizontal wind speed and direction, vertical velocity variance, and aerosol backscatter intensity every $20 \mathrm{~min}$ (http://www.esrl.noaa.gov/csd/ groups/csd3/measurements/influx/latest.html, accessed 14 April 2014). Such data will also help us determine the history of the winds prior to the mass balance experiment and assess the impact of any changing winds on the estimated flux. High-frequency determinations of CBL depth with the lidar will free up flight time for acquisition of more downwind horizontal transect data. As shown here, the process of interpolation also introduces uncertainties into the budget calculation, especially in the limit of a small number of transects. Therefore, multiple horizontal transects will minimize interpolation-related uncertainties. That recommendation is best implemented with higher aircraft speed.

We also noted that the UHI dilution of the background brought about by differences in entrainment rate inside and outside the city may also contribute significantly to our uncertainty budget. We can determine the impact of the UHI effect more accurately in future flight experiments by conducting vertical profiles upwind of the city and comparing with the simultaneous wind lidar measurements installed in the city. This will then enable the quantification of the difference in CBL depth inside and outside the city, as well as the impact of this difference on the background inflow into the city.

We also evaluated the precision of the approach by comparing measurements made in rapid succession over transects at multiple downwind distances from three point (or small area) sources with large strengths. We obtained relative differences ranging from 12 to $52 \%$, with an average of $\sim 30 \%$. Given that these experiments were conducted downwind of sources with large source strengths and smaller areal footprints, which effectively minimize the background variability problem, as well as changes in the boundary layer over the course of the longer citywide experiments, we thus conservatively estimate the overall uncertainty (precision plus systematic errors) for individual urban flux measurements as $\pm 50 \%$ (maximum relative difference rounded off to the nearest $10 \%$ ). This is consistent with the average difference between our determinations of the HSPP flux and the EPA CEMS data for the flight dates studied here.

We also compared the multi-transect kriging approach with results from single-transect realizations of the flux, assuming a well-mixed boundary layer. Our results suggest that there is a trade-off between the necessary downwind distance for complete mixing and the ratio of the enhancement to the uncertainty in the background concentration. Thus, we recommend that multiple transects through the boundary layer be pursued when possible. We observed that the variability of the estimated flux from the single-transect method ranged from 23 to $65 \%$, which treats each transect as a single realization of the flux, while the interpolation method treats all the data as a single realization and does not assume that there is complete mixing throughout the boundary layer.

\section{The Supplement related to this article is available online at doi:10.5194/acp-14-9029-2014-supplement.}

Acknowledgements. This research work is part of the Indianapolis Flux Experiment (INFLUX), which is funded by NIST. We also thank the Purdue University Jonathan Amy Facility for Chemical Instrumentation (JAFCI) for technical support in this project. Many thanks also go to Kuldeep Prasad of NIST for his helpful comments in this manuscript.

Disclaimer. Some commercial instruments are identified to represent the data sources accurately. Such identification does not imply recommendation or endorsement by the National Institute of Standards and Technology, nor does it imply that the equipment identified is necessarily the best available for the purpose.

Edited by: T. Karl

\section{References}

Angevine, W. M., White, A. B., Senff, C. J., Trainer, M., Banta, R. M., and Ayoub, M. A.: Urban-rural contrasts in mixing height and cloudiness over Nashville in 1999, J. Geophys. Res., 108, 4092, doi:10.1029/2001JD001061, 2003.

Bergamachi, P., Krol, M., Meirink, J. F., Dentener, F., Segers, A., van Aardenne, J., Monni, S., Vermeulen, A. T., Schmidt, M., Ramonet, M., Yver, C., Meinhardt, F., Nisbet, E. G., Fisher, R. E., O'Doherty, S., and Dlugokencky, E. J.: Inverse modeling of European $\mathrm{CH}_{4}$ emissions 2001-2006, J. Geophys. Res., 115, D22309, doi:10.1029/2010JD014180, 2010.

Boden, T. A., Marland, G., and Andres, R. J.: Global, Regional, and National Fossil-Fuel $\mathrm{CO}_{2}$ Emissions. Carbon Dioxide Information Analysis Center, Oak Ridge National Laboratory, US Department of Energy, Oak Ridge, Tenn., USA, doi:10.3334/CDIAC/00001_V2010, 2010.

Brioude, J., Angevine, W. M., Ahmadov, R., Kim, S.-W., Evan, S., McKeen, S. A., Hsie, E.-Y., Frost, G. J., Neuman, J. A., Pollack, I. B., Peischl, J., Ryerson, T. B., Holloway, J., Brown, S. S., Nowak, J. B., Roberts, J. M., Wofsy, S. C., Santoni, G. W., Oda, T., and Trainer, M.: Top-down estimate of surface flux in the Los Angeles Basin using a mesoscale inverse modeling technique: assessing anthropogenic emissions of $\mathrm{CO}, \mathrm{NO}_{\mathrm{x}}$ and $\mathrm{CO}_{2}$ and their impacts, Atmos. Chem. Phys., 13, 3661-3677, doi:10.5194/acp13-3661-2013, 2013. 
Cambaliza, M. O. L., Shepson, P. B., Bogner, J., Caulton, D. R., Stirm, B., Sweeney, C., Montzka, S. A., Gurney, K. R., Spokas, K., Salmon, O. E., Lavoie, T. N., Hendricks, A., Mays, K., Turnbull, J., Miller, B. R., Lauvaux, T., Davis, K., Karion, A., Moser, B., Miller, C., Obermeyer, C., Whetstone, J., Prasad, K., Miles, N., and Richardson, S.: Quantification and source apportionment of the methane emission flux from the city of Indianapolis, Elementa, submitted, 2014.

Chen, H., Winderlich, J., Gerbig, C., Hoefer, A., Rella, C. W., Crosson, E. R., Van Pelt, A. D., Steinbach, J., Kolle, O., Beck, V., Daube, B. C., Gottlieb, E. W., Chow, V. Y., Santoni, G. W., and Wofsy, S. C.: High-accuracy continuous airborne measurements of greenhouse gases $\left(\mathrm{CO}_{2}\right.$ and $\left.\mathrm{CH}_{4}\right)$ using the cavity ringdown spectroscopy (CRDS) technique, Atmos. Meas. Tech., 3, 375-386, doi:10.5194/amt-3-375-2010, 2010.

Chu, D.: The GLOBEC kriging software package - EasyKrig3.0; The Woods Hole Oceanographic Institution: 2004, available at: http://globec.whoi.edu/software/kriging/easy_krig/easy_krig. html, last access: January 2011.

Ciais, P., Paris, J., Marland, G., Peylin, P., Piao, S., Levin, I., Pregger, T., Scholz, Y., Friedrich, R., Houwelling, S., and Schulze, D.: The European carbon balance revisited. Part 1: fossil fuel emissions, Glob. Change Biol., 16, 1395-1408, doi:10.1111/j.13652486.2009.02098.x, 2010.

Clyde, M. and George, E. I.: Model uncertainty, Stat. Sci., 19, 8194, 2004.

Consumer News and Business Channel: http://www.cnbc.com/id/ 39382002/America_s_Largest_Landfills, last access: 6 September 2012 .

Conway, T. J., Tans, P. P., Waterman, L. S., Thoning, K. W., Kitzis, D. R., Masarie, K. A., and Zhang, N.: Evidence for interannual variability of the carbon cycle from the NOAA/CMDL global air sampling network, J. Geophys. Res., 99, 22831-22855, 1994.

Crosson, E. R.: A cavity ring-down analyzer for measuring atmospheric levels of methane, carbon dioxide, and water vapor, Appl. Phys. B Lasers O., 92, 403-408, 2008.

Dlugokencky, E. J., Masarie, K. A., Lang, P. M., Tans, P. P., Steele, L. P., and Nisbet, E. G.: A dramatic decrease in the growth rate of atmospheric methane in the northern hemisphere during 1992, Geophys. Res. Lett., 21, 45-48, 1994.

Dlugokencky, E. J., Myers, R., Lang, P., Masarie, K., Crotwell, A., Thoning, K., Hall, B., Elkins, J., and Steele, L. P. : Conversion of NOAA/CMDL Atmospheric Dry Air $\mathrm{CH}_{4}$ Mole Fractions to a Gravimetrically Prepared Standard Scale, J. Geophys. Res., 110, D18306, doi:10.1029/2005JD006035, 2005.

Draxler, R. R. and Rolph, G. D.: HYSPLIT (HYbrid Single-Particle Lagrangian Integrated Trajectory) Model access via NOAA ARL READY Website (http://ready.arl.noaa.gov/HYSPLIT. php), NOAA Air Resources Laboratory, Silver Spring, MD, 2012.

Fan, J. and Gijbels, I.: Local Polynomial Modeling and Its Applications, Chapman \& Hall, 1996.

Forster, P., Ramaswamy, V., Artaxo, P., Berntsen, T., Betts, R., Fahey, D. W., Haywood, J., Lean, J., Lowe, D. C., Myhre, G., Nganga, J., Prinn, R., Raga, G., Schulz, M., and Van Dorland, R.: Changes in Atmospheric Constituents and in Radiative Forcing, in: Climate Change 2007: The Physical Science Basis. Contribution of Working Group I to the Fourth Assessment Report of the Intergovernmental Panel on ClimateChange, edited by: Solomon,
S., Qin, D., Manning, M., Chen, Z., Marquis, M., Averyt, K. B., Tignor, M., and Miller, H. L., Cambridge UniversityPress, Cambridge, United Kingdom and New York, NY, USA, 2007.

Garman, K. E.: Precision of airborne wind measurement for atmospheric flight research, Ph.D. dissertation, Purdue University, USA, 2009.

Garman, K. E., Hill, K. A., and Wyss, P., Carlsen, M., Zimmerman, J. R., Stirm, B. H., Carney, T. Q., Santini, R., and Shepson, P. B.: An airborne and wind tunnel evaluation of a wind turbulence measurement system for aircraft-based flux measurements, J. Atmos. Ocean. Tech., 23, 1696-1708, 2006.

Garman, K. E., Wyss, P., Carlsen, M., Zimmerman, J. R., Stirm, B. H., Carney, T. Q., Santini, R., and Shepson, P. B.: The contribution of variability of lift-induced upwash to the uncertainty in vertical winds determined from an aircraft platform, Bound. Lay. Meteorol., 126, 461-476, 2008.

Gregg, J. S., Andres, R. J., and Marland, G.: China: Emissions pattern of the world leader in $\mathrm{CO}_{2}$ emissions from fossil fuel consumption and cement production, Geophys. Res. Lett., 35, L08806, doi:10.1029/2007GL032887, 2008.

Guan, D., Liu, Z., Geng, Y., Lindner, S., and Hubacek, K.: The gigatonne gap in China's carbon dioxide inventories, Nature Clim. Change, 2, 672-675, doi:10.1038/NCLIMATE1560, 2012.

Gurney, K. R., Mendoza, D. L., Zhou, Y., Fischer, M. L., Miller, C. C., Geethakumar, S., and de la Rue du Can, S.: High resolution fossil fuel combustion $\mathrm{CO}_{2}$ emission fluxes for the United States, Environ. Sci. Technol., 43, 5535-5541, doi:10.1021/es900806c, 2009.

Gurney, K. R., Razlivanov, I., Song, Y., Zhou, Y., Benes, B., and Abdul-Massih, M.: Quantification of fossil fuel $\mathrm{CO}_{2}$ emissions at the building/street level scale for a large US city, Environ. Sci. Technol., 46, 12194-12202, doi:10.1021/es3011282, 2012.

Helman, C.: America's Biggest Landfills, http://www.forbes.com/2010/10/13/los-angeles-las-vegas, last access: 6 September 2012.

Indiana Department of Environmental Management Confined Feeding Operations, http://www.in.gov/idem/4994.htm, last access: 6 September 2012.

International Energy Agency: World Energy Outlook, 2008, IEA, Paris, France, 2008.

Johnson, K., Huyler, M., Westberg, H., Lamb, B., and Zimmerman, P.: Measurement of methane emissions from ruminant livestock using a $\mathrm{SF}_{6}$ Tracer Technique, Environ. Sci. Technol., 28, 359362, 1994.

Kalthoff, N., Corsmeier, U., Schmidt, K., Kottmeier, Ch., Fiedler, F., Habram, M., and Slemr, F.: Emissions of the city of Augsburg determined using the mass balance method, Atmos. Environ., 36, S19-S31, 2002.

Karion, A., Sweeney, C., Wolter, S., Newberger, T., Chen, H., Andrews, A., Kofler, J., Neff, D., and Tans, P.: Long-term greenhouse gas measurements from aircraft, Atmos. Meas. Tech., 6, 511-526, doi:10.5194/amt-6-511-2013, 2013a.

Karion, A., Sweeney, C., Petron, G., Frost, G., Hardesty, R. M., Kofler, J., Miller, B. R., Newberger, T., Wolter, S., Banta, R., Brewer, A., Dlugokencky, E., Lang, P., Monztka, S. A., Schnell, R., Tans, P., Trainer, M., Zamora, R., and Conley, S.: Methane emissions estimates from airborne measurements over a western United States natural gas field, Geophys. Res. Lett., 40, 1-5, doi:10.1002/grl.50811, 2013b. 
Kort, E. A., Frankenberg, C., Miller, C. E., and Oda, T.: Space-based observations of megacity carbon dioxide, Geophys. Res. Lett., 39, L17806, doi:10.1029/2012GL052738, 2012.

Lafferty, J. and Wasserman, L.: Rodeo: Sparse, greedy nonparametric regression, Ann. Stat., 36, 28-63, 2008.

Lenschow, D. H. and Stankov, B. B.: Length scales in the convective boundary layer, J. Atmos. Sci., 43, 1198-1209, 1986.

Marland, G.: Uncertainties in accounting for $\mathrm{CO}_{2}$ from fossil fuels, J. Ind. Ecol., 12, 136-139, doi:10.1111/j.15309290.2008.00014.x, 2008.

Marland, G.: China's uncertain $\mathrm{CO}_{2}$ emissions, Nature Clim. Change, 2, 645-646, 2012.

Mays, K. L., Shepson, P. B., Stirm, B. H., Karion, A., Sweeney, C., and Gurney, K. R.: Aircraft-based Measurements of the Carbon Footprint of Indianapolis, Environ. Sci. Technol., 43, 7816-7823, 2009.

McKain, K., Wofsy, S. C., Nehrkorn, T., Eluszkiewicz, J., Ehleringer, J. R., and Stephens, B. B.: Assessment of groundbased atmospheric observations for verification of greenhouse gas emissions from an urban region, P. Natl. Acad. Sci. USA, 109, 8423-8428, doi:10.1073/pnas.1116645109, 2012.

Miles, N., Lauvaux, T., Davis, K., Richardson, S., McGowan, L., Sarmiento, D., Sweeney, C., Karion, A., Hardesty, M., Turnbull, J., Iraci, L., Gurney, K. R., Razlivanov, I., Cambaliza, M. O., Shepson, P., and Whetstone, J.: On network design for the detection of urban greenhouse gas emissions: Results from the Indianapolis Flux Experiment (INFLUX), AGU Fall Meeting, San Francisco, California, USA, 9-13 December 2013, A44F01, 2013.

Montzka, S. A., Myers, R. C., Butler, J. H., Elkins, J. W., and Cummings, S.: Global tropospheric distribution and calibration scale of HCFC-22, Geophys. Res. Lett., 20, 703-706, 1993.

Peischl, J., Ryerson, T. B., Brioude, J., Aikin, K. C., Andrews, A. E., Atlas, E., Blake, D., Daube, B. C., de Gouw, J. A., Dlugokencky, E., Frost, G. J., Gentner, D. R., Gilman, J. B., Goldstein, A. H., Harley, R. A., Holloway, J. S., Kofler, J., Kuster, W. C., Lang, P. M., Novelli, P. C., Santoni, G. W., Trainer, M., Wofsy, S. C., and Parish, D. D.: Quantifying sources of methane using light alkanes in the Los Angeles basin, California, J. Geophys. Res. Atmos., 118, 4974-4990, doi:10.1002/jgrd.50413, 2013.

Peters, G. P., Marland, G., Le Quere, C., Boden, R., Canadell, J. G., and Raupach, M. R.: Rapid growth in $\mathrm{CO}_{2}$ emissions after the 2008-2009 global financial crisis, Nature Clim. Change, 2, 2-4, 2012.

Peylin, P., Houweling, S., Krol, M. C., Karstens, U., Rödenbeck, C., Geels, C., Vermeulen, A., Badawy, B., Aulagnier, C., Pregger, T., Delage, F., Pieterse, G., Ciais, P., and Heimann, M.: Importance of fossil fuel emission uncertainties over Europe for $\mathrm{CO}_{2}$ modeling: model intercomparison, Atmos. Chem. Phys., 11, 66076622, doi:10.5194/acp-11-6607-2011, 2011.

Ryerson, T. B., Trainer, M., Holloway, J. S., Parrish, D. D., Huey, L. G., Sueper, D. T., Frost, G. J., Donnelly, S. G., Schauffler, S., Atlas, E. L., Kuster, W. C., Goldan, P. D., Hubler, G., Meagher, J. F., and Fehsenfeld, F.C.: Observations of ozone formation in power plant plumes and implications for ozone control strategies, Science, 292, 719-723, doi:10.1126/science.1058113, 2001.
Samarov, D. V.: The Fast Rodeo for Local Polynomial Regression, Technical Report, National Institute of Standards and Technology, 2012.

Solid Waste Facility Annual Report for the State of Indiana, http:// www.in.gov/idem/files/solid_waste_fdr08.pdf (last access: May 2011), 2008

Stull, R. B.: An Introduction to Boundary Layer Meteorology, Kluwer Academic Publishers, Dordrecht, The Netherlands, 1997.

Trainer, M., Ridley, B. A., Buhr, M. P., Kok, G., Walega, J., Hubler, G., Parrish, D. D., and Fehsenfeld, F. C.: Regional ozone and urban plumes in the southeastern United States: Birminghan, a case study, J. Geophys. Res., 100, 18823-18834, 1995.

Turnbull, J. C., Lehman, S. J., Miller, J. B., Sparks, R. J., Southon, J. R., and Tans, P. P.: A new high precision ${ }^{14} \mathrm{CO}_{2}$ time series for North American continental air, J. Geophys. Res., 112, D11310, doi:10.1029/2006JD008184, 2007.

Turnbull, J. C., Karion, A., Fischer, M. L., Faloona, I., Guilderson, T., Lehman, S. J., Miller, B. R., Miller, J. B., Montzka, S. Sherwood, T., Saripalli, S., Sweeney, C., and Tans, P. P.: Assessment of fossil fuel carbon dioxide and other anthropogenic trace gas emissions from airborne measurements over Sacramento, California in spring 2009, Atmos. Chem. Phys., 11, 705-721, doi:10.5194/acp-11-705-2011, 2011.

Turnbull, J. C., et al.: Towards quantification and source sector identification of fossil fuel $\mathrm{CO}_{2}$ emissions from an urban area: Results from the INFLUX experiment, in preparation, 2014.

United States Environmental Protection Agency Air Markets Program Data: http://ampd.epa.gov/ampd/, last access: August 2012.

United States Environmental Protection Agency Greenhouse Gas Data: http://ghgdata.epa.gov/ghgp/main.do, last access: 2 September 2012.

Vaughn, B. H., Ferretti, D. F., Miller, J. B., and White, J. W. C.: Stable isotope measurements of atmospheric $\mathrm{CO}_{2}$ and $\mathrm{CH}_{4}$, in: Handbook of stable isotope analytical techniques, Elsevier BV, Amsterdam, The Netherlands, 2004.

Walter, D., Heue, K.-P., Rauthe-Schoch, A., Brenninkmeijer, C. A. M., Lamsal, L. N., Krotkov, N. A., and Platt, U.: Flux calculations using CARIBIC DOAS aircraft measurements: $\mathrm{SO}_{2}$ emission of Norilsk, J. Geophys. Res., 117, D11305, doi:10.1029/2011JD017335, 2012.

Westberg, H., Lamb, B., Johnson, K. A., and Huyler, M.: Inventory of methane emissions from U.S. cattle, J. Geophys. Res., 106, 12633-12642, 2001.

White, W. H., Anderson, J. A., Blumenthal, D. L., Husar, R. B., Gillani, N. V., Husar, J. D., and Wilson Jr., W. E.: Formation and Transport of Secondary Air Pollutants: Ozone and Aerosols in the St. Louis Urban Plume, Science, 194, 187-189, 1976.

White, W. H., Patternson, D. E., and Wilson Jr., W. E.: Urban exports to the nonurban Troposphere: Results from Project MISTT, J. Geophys. Res., 88, 10745-10752, 1983.

World Bank: Cities and Climate Change: An Urgent Agenda, Vol. 10, Washington, DC, USA, 2010.

Wratt, D. S., Gimson, N. R., Brailsford, G. W., Lassey, K. R., Bromley, A. M., and Bell, M. J.: Estimating regional methane emissions from agriculture using aircraft measurements of concentration profiles, Atmos. Environ., 35, 497-508, 2001. 
Wunch, D., Wennberg. P. O., Toon, G. C., Keppel-Aleks, G., and Yavin, Y. G.: Emissions of greenhouse gases from a North American megacity, Geophys. Res. Lett., 36, L15810, doi:10.1029/2009GL039825, 2009.
Zhao, C. L. and Tans, P. P.: Estimating uncertainty of the WMO mole fraction scale for carbon dioxide in air, J. Geophys. Res., 111, D08S09, doi:10.1029/2005JD006003, 2006. 